
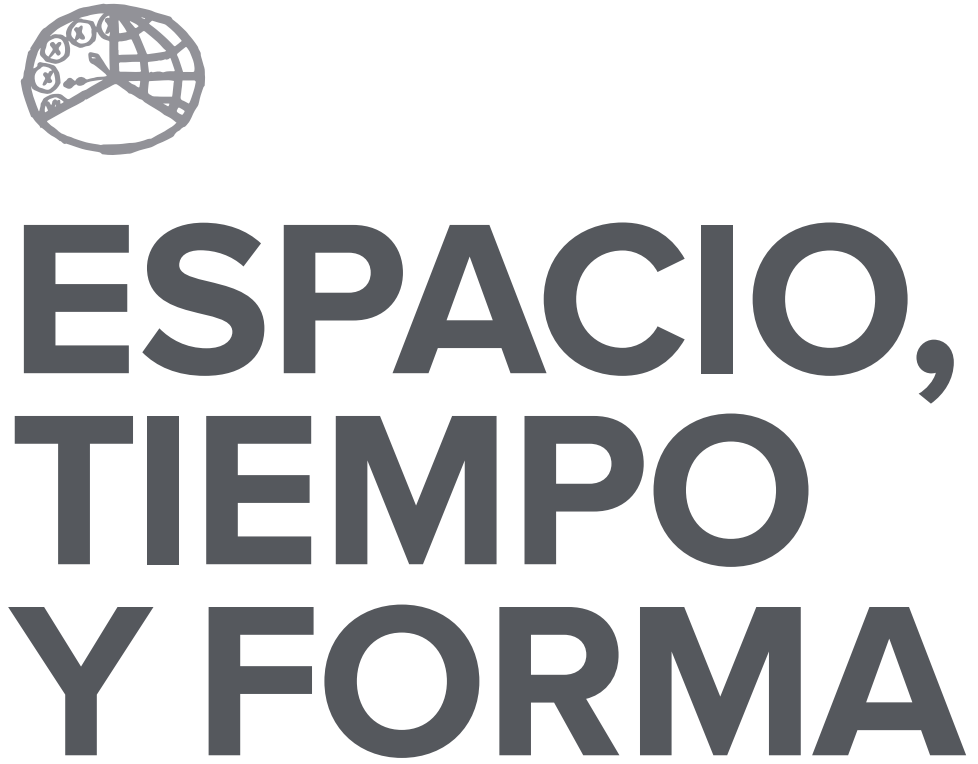

AÑO 2021

ISSN 0214-9745

E-ISSN 2340-1362

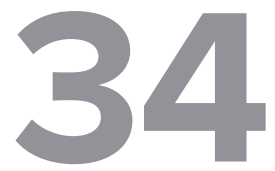

SERIE III HISTORIA MEDIEVAL

REVISTA DE LA FACULTAD DE GEOGRAFÍA E HISTORIA

VOLUMEN I 


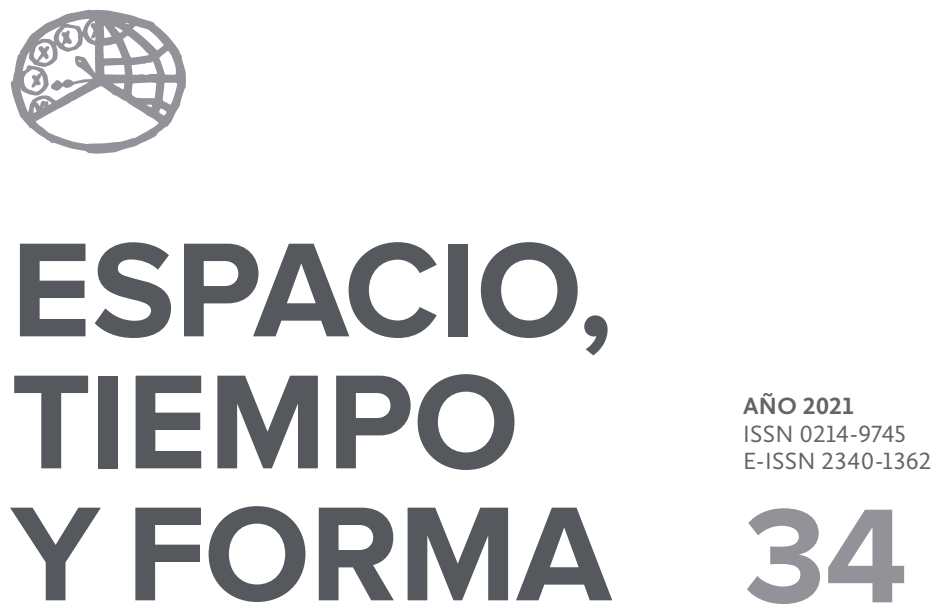

SERIE III HISTORIA MEDIEVAL

REVISTA DE LA FACULTAD DE GEOGRAFÍA E HISTORIA

VOLUMEN I

http://dx.doi.org/10.5944/etfiii.34.2021

\section{UกED}

UNIVERSIDAD NACIONAL DE EDUCACIÓN A DISTANCIA 
La revista Espacio, Tiempo y Forma (siglas recomendadas: ETF),

de la Facultad de Geografía e Historia de la UNED, que inició su publicación el año 1988, está organizada de la siguiente forma:

$$
\begin{aligned}
& \text { SERIE I - Prehistoria y Arqueología } \\
& \text { SERIE II - Historia Antigua } \\
& \text { SERIE III - Historia Medieval } \\
& \text { SERIE IV - Historia Moderna } \\
& \text { SERIE V - Historia Contemporánea } \\
& \text { SERIE VI - Geografía } \\
& \text { SERIE VII - Historia del Arte }
\end{aligned}
$$

Excepcionalmente, algunos volúmenes del año 1988 atienden a la siguiente numeración:
N. ${ }^{\circ} 1 \quad-$ Historia Contemporánea
N. ${ }^{\circ} 2-$ Historia del Arte
N. ${ }^{\circ} 3-$ Geografía
N. ${ }^{\circ} 4 \quad-$ Historia Moderna

ETF no se solidariza necesariamente con las opiniones expresadas por los autores.

UNIVERSIDAD NACIONAL DE EDUCACIÓN A DISTANCIA

Madrid, 2021

SERIE III - HISTORIA MEDIEVAL N. ${ }^{\circ} 34,2021$

ISSN 0214-9745 · E-ISSN 2340-1362

DEPÓSITO LEGAL M-21037-1988

URL: ETF III · HISTORIA MEDIEVAL · http://revistas.uned.es/index.php/ETFIII

DISEÑO Y COMPOSICIÓN

Carmen Chincoa Gallardo · http://www.laurisilva.net/cch

Impreso en España $\cdot$ Printed in Spain 
Espacio, Tiempo y Forma. Serie III. Historia Medieval es la revista científica fundada en I988 que publica el Departamento de Historia Medieval y Ciencias y Técnicas Historiográficas de la Facultad de Geografía e Historia de la UNED. Está dedicada al estudio de la Historia Medieval y acoge trabajos inéditos de investigación, en especial artículos que constituyan una aportación novedosa, que enriquezcan el campo de estudio que abordan y que ofrezcan una perspectiva de análisis crítico. Va dirigida preferentemente a la comunidad científica y universitaria, tanto nacional como internacional, así como a todos los profesionales de la Historia Medieval en general. Su periodicidad es anual y se somete al sistema de revisión por pares ciegos. La revista facilita el acceso sin restricciones a todo su contenido desde el momento de su publicación en edición electrónica. Espacio, Tiempo y Forma. Serie III. Historia Medieval se publica en formato electrónico y en papel.
Espacio, Tiempo y Forma. Serie III. Historia Medieval (Space, Time and Form. Series III. Medieval History) is a peerreviewed academic journal founded in I988 and published by the Department of Medieval History and Historiographical Sciences and Techniques at the Faculty of Geography and History, UNED. It is devoted to the study of Medieval History and is addressed to the Spanish and international scholarly community, as well as to professionals in the field of Medieval History. The journal welcomes previously unpublished articles, particularly works that provide an innovative approach, contribute to its field of research and offer a critical analysis. It is published annually. The journal provides complete open access to its content available online upon publication. Espacio, Tiempo y Forma. Serie III. Historia Medieval is published online and in print and is indexed in the databases and directories enumerated below.

Espacio, Tiempo y Forma. Serie III. Historia Medieval está registrada e indexada en Repertorios Bibliográficos y Bases de Datos nacionales e internacionales, como recomiendan los criterios de la Comisión Nacional Evaluadora de la Actividad Investigadora: LATINDEX, DICE, ISOC (CINDOC), RESH, INRECH, Dialnet, e-spacio UNED, CIRC 2.o (20I6), MIAR, FRANCIS, PIO, Ulrich's, SUDOC, ZDB, ERIH (ESF), REDIB, Repertorio de Medievalismo Hispánico, Directory of Open Access Journals (DOAJ), Emerging Sources Citation Index (ESCI), SCOPUS. La revista ha obtenido el Sello de Calidad de la FECYT (2018).

\section{EQUIPO EDITORIAL}

Edita: Departamento de Historia Medieval y Ciencias y Técnicas Historiográficas, Universidad Nacional de Educación a Distancia

Director del Consejo de Redacción: Enrique Cantera Montenegro (UNED)

Editores: Enrique Cantera Montenegro (UNED), Carlos Barquero Goñi (UNED) 
CONSEJO DE REDACCIÓN

Cristina Álvarez Millán

Departamento de Historia Medieval y Ciencias y Técnicas Historiográficas, UNED

Ana Arranz Guzmán

Universidad Complutense de Madrid

Carlos de Ayala Martínez

Universidad Autónoma de Madrid

Carlos Barquero Goñi

Departamento de Historia Medieval y Ciencias y Técnicas Historiográficas, UNED

Enrique Cantera Montenegro

Departamento de Historia Medieval y Ciencias y Técnicas Historiográficas, UNED

Ana Echevarría Arsuaga

Departamento de Historia Medieval y Ciencias y Técnicas Historiográficas, UNED

José María de Francisco Olmos

Universidad Complutense de Madrid

María Jesús Fuente Pérez

Universidad Carlos III de Madrid

Manuel Fernando Ladero Quesada

Departamento de Historia Medieval y Ciencias y Técnicas Historiográficas, UNED

Paulina López Pita

Departamento de Historia Medieval y Ciencias y Técnicas Historiográficas, UNED

José Miguel López Villalba

Departamento de Historia Medieval y Ciencias y Técnicas Historiográficas, UNED

José María Monsalvo Antón

Universidad de Salamanca

Isabel Montes Romero-Camacho

Universidad de Sevilla

Gonzalo Viñuales Ferreiro

Universidad Rey Juan Carlos

COMITÉ CIENTÍFICO

Vicente Ángel Álvarez Palenzuela

Universidad Autónoma de Madrid

Daniel Baloup

Université de Toulouse-Le Mirail

Vicente García Lobo

Universidad de León

María Estela González de Fauve

Universidad de Buenos Aires · Fundación para la Historia de España

César González Mínguez

Universidad del País Vasco 
Nikolas Jaspert

Ruhr-Universität Bochum, Alemania

DIRECTORA DE ETF SERIES I-VII

Yayo Aznar Almazán

Decana Facultad de Geografía e Historia, UNED

SECRETARIO DE ETF SERIES I-VII

Julio Fernández Portela

Departamento de Geografía, UNED

GESTORA PLATAFORMA OJS

Carmen Chincoa Gallardo

COMITÉ EDITORIAL DE ETF SERIES I-VII

Carlos Barquero Goñi, Departamento de Historia Medieval y Ciencias y Técnicas Historiográficas, UNED; Enrique Cantera Montenegro, Departamento de Historia Medieval y Ciencias y Técnicas Historiográficas, Uned; Pilar Díez del Corral Corredoira, Departamento de Historia del Arte, UneD; Carmen Guiral Pelegrín, Departamento de Prehistoria y Arqueología (Arqueología), Uned; Patricia Hevia Gómez, Departamento de Prehistoria y Arqueología (Arqueología), unED; Luiza lordache Cârstea, Departamento de Historia Contemporánea, UNED; M. ${ }^{a}$ Luisa de Lázaro Torres, Departamento de Geografía, Uned; David Martín Marcos, Departamento de Historia Moderna, Uned; José Antonio Martínez Torres, Departamento de Historia Moderna, UnED; Íñigo García Martínez de Lagrán, Departamento de Prehistoria y Arqueología (Prehistoria), UnED; Álvaro Molina Martín, Departamento de Historia del Arte, Uned; Francisco Javier Muñoz Ibáñez, Departamento de Prehistoria y Arqueología (Prehistoria), UNED; Rocío Negrete Peña, Departamento de Historia Contemporánea, UnED; Miguel Ángel Novillo López, Departamento de Historia Antigua, UnED.

CORRESPONDENCIA

Revista Espacio, Tiempo y Forma

Facultad de Geografía e Historia, UNED

c/ Senda del Rey, 7

28040 Madrid

e-mail: revista-etf@geo.uned.es 



\section{SUMARIO · SUMMARY}

\section{VOLUMEN I}

13 Artículos $\cdot$ Articles

15 Patricia A. Argüelles Álvarez

Peligros, inseguridades y problemas del viajero visigodo

Danger, Lack of Safety and Problems for the Visigothic Traveller

37 Carmen Barceló, Ana labarta, Josep Benedito \& José M. Melchor Cuatro cerámicas con epigrafía árabe del Museu de Borriana

Four Ceramic Pieces with Arabic Inscriptions in the Archeological Museum of Borriana

65 Carlos Barquero Goñ

Organización de la Orden de San Juan en Castilla durante los siglos XII y XIII The Organization of the Order of Saint John in Castile during the Twelfth and Thirteenth Centuries

113 Francisco de Paula Cañas Gálvez

Una infanta de Navarra en la corte de Castilla: escenarios políticos en torno a la configuración y evolución del Hostal y la casa de Blanca de Trastámara, Princesa de Asturias (I424-†I464)

A Princess of Navarre in the Court of Castile: Political Scenarios in the Configuration and Evolution of the Hostal and Royal Household of Blanca of Trastámara, Princess of Asturias (I424-†I464)

165 David Caramazana Malia

Las promociones artísticas de Alonso de Ejea, arzobispo y administrador perpetuo de la Archidiócesis de Sevilla y patriarca de Constantinopla (I403-I4I7)

The Artistic Patronage of Alonso de Ejea, Archbishop and Perpetual Administrator of the Archdiocese of Seville and Patriarch of Constantinople (I403-I4I7) 
203 Pedro Castillo Maldonado

Privilegios episcopales: la inviolabilidad de los obispos visigóticos y el delito de lesa majestad

Episcopal Privileges: The Inviolability of Visigothic Bishops and the Crime of Lèse-Majesté

227 Máximo Diago HERnANDO

Alonso de Fonseca, Obispo de Ávila, Cuenca y Osma, y el ascenso de un linaje de exiliados portugueses en la Castilla de los siglos XV y XVI Alonso de Fonseca, Bishop of Ávila, Cuenca and Osma, and the Promotion in Castile of an Exiled Noble Family from Portugal during the Fifteenth and Sixteenth Centuries

263 Antonio PIO DI Cosmo

Santa Brigida ed il Monte Gargano: un paesaggio dell'anima. La descrizione dell'ambiente come stratagemma d'ammaestramento morale Saint Brigid and Mount Gargano: A Landscape of the Soul. The Description of the Environment as a Device for Moral Instruction

Santa Brígida y el Monte Gargano: un paisaje del alma. La descripción del medio ambiente como estrategia de entrenamiento moral

293 FERRAN ESQUiLACHE

La 'fila' de agua valenciana y otras medidas de aforo. La verdadera naturaleza de un sistema de medición de caudales de origen andalusí

The Valencian Water 'Fila' and other Systems of Gauging Liquid Capacity. The Actual Nature of a Measurement System of Water Flow of Andalusí Origin

323 Alejandro Esteban Álvarez

Habices del Reino de Granada averiguados en I528 y I53I: la țā‘a nazarí de Órgiva (Alpujarra)

Habices of the Kingdom of Granada Ascertained in 1528 and I53I: The Nasrid tạa'a of Órgiva (Alpujarra)

359 Javier Gómez Gómez e Iñakı Martín Viso

Rationes y decimas: evidencias sobre la gestión de las sernas en el siglo Xl en el noroeste de la Península Ibérica

Rationes and Decimas: Some Evidences on the Management of Eleventh Century Sernas in Northwestern Iberia 
383 Santiago González Sánchez

Aportaciones de Paredes de Nava a las campañas militares del Infante Don Fernando, señor de la villa y regente de Castilla, contra el Reino Nazarí de Granada en I407 y en I4IO

The Contribution of Paredes de Nava to the Military Campaigns of the Infante Fernando, Lord of the Town and Regent of Castile, against the Nasrid Kingdom of Granada in 1407 and I4IO

429 ANTONI LLIBRER ESCRIG

Una máquina para la industria medieval. Los batanes del sur valenciano: integración y negocio. Nuevas aportaciones (I49O-I502)

A Machine for Medieval Industry. The Fulling Mills of the Valencian South: Integration and Business. New contributions (I49O-I502)

455 José Miguel López Villalba

Comunicación escrita y oral de la ordenanza municipal (siglos XV-XVI) Written and Oral Communication of Municipal Regulations (FifteenthSixteenth Centuries)

501 Emilio Martín Gutiérrez

El aprovechamiento de los recursos naturales: la grana en Andalucía occidental durante el siglo XV

The Use of Natural Resources: Grana Pigmentin Western Andalusia during the Fifteenth Century

\section{VOLUMEN II}

537 Vera-Cruz Miranda Menacho

Las finanzas de un heredero: Carlos de Aragón y Navarra (I42I-I46I)

A Crown Prince's Finances: Charles of Aragon and Navarre (I42I-I46I)

569 Raúl Morales Muñoz

Hacia una revalorización del conciliarismo hispano bajomedieval: el Defensorium Trium Conclusionum de Alfonso de Madrigal

Towards a Reappraisal of Late-Medieval Hispanic Conciliarism: Alfonso de Madrigal's Defensorium Trium Conclusionum 
605 David Nogales Rincón

Enrique III de Castilla (I390-I406) y la indagación de rentas: un proyecto regio para la búsqueda de mineros y tesoros a inicios del cuatrocientos Enrique III of Castile (I390-I406) and the Inquiry into Sources of Revenue: A Royal Project for the Quest of Mines And Treasures at the Turn of the Fifteenth Century

647 Gonzalo Oliva Manso

Seisenes y novenes. Tiempos de calma para la moneda castellano-leonesa (I282-I3I2)

The Seisén and the Novén. Times of Stability for the Castile-Leonese Currency (I282-I3I2)

685 Alberto Peña Fernández y Manuel García Alonso Una inscripción medieval inédita en la iglesia de San Miguel de Aguayo (Cantabria)

A Newly Found Medieval Inscription in the Church of San Miguel de Aguayo (Cantabria)

713 Rodrigo Pousa Diéguez

Configuración institucional de una villa costera: Muros en el tránsito de la Edad Media a la Edad Moderna

The Institutional Development of a Coastal Village: Muros between the Middle Ages and the Early Modern Times

745 Juan A. Prieto Sayagués

Las profesiones femeninas de la nobleza y de las oligarquías urbanas en la Castilla bajomedieval. Causas, dinámicas, privilegios y donaciones

Female Professions among the Nobility and the Urban Oligarchy in Late Medieval Castile. Causes, Dynamics, Privileges and Donations

815 María del Pilar Rábade Obradó

El miedo a la Inquisición en la Castilla de los Reyes Católicos

Fear of the Inquisition in Castile under the Catholic Monarchs

845 Carlos Manuel Reglero de la Fuente

EL abad contra el rey (y los regidores): conflicto de jurisdicciones y ejercicio del poder en Sahagún (I398-I4I7)

The Abbot versus The King (and the Town Councillors): Conflict between Jurisdictions and the Use of Power in Sahagún (I398-I4I7) 
881 Manuel Alejandro Rodríguez de la Peña

Eusebius and Alcuin on Constantine and Charlemagne as Wise Rulers:

Sapiential Rulership in Late Antiquity and the Early Middle Ages

Constantino y Carlomagno como gobernantes sabios en la obra de Eusebio de Cesarea y Alcuino de York: la realeza sapiencial en la Antigüedad Tardía y la Alta Edad Media

915 Antonio SÁnchez González

El Archivo de los Mariscales de Castilla y Marqueses de Malagón

The Archives of the Marshals of Castile and the Marquises of Malagón

\section{Estudios y comentarios}

951 Serafín Olcoz Yanguas

Apostilla al estudio Influencia de las redes nobiliarias en la expansión cristiana del siglo XII: el caso de Soria (ETF, 33, 2020)

Notes on the Article The Influence of Aristocratic Networks on the Christian Expansion of the Twelfth Century. The Case of Soria $(E T F, 33,2020)$

\section{Libros $\cdot$ Books}

969 CASTRIllo CASAdo, Janire, Las mujeres vascas durante la Baja Edad Media (María Jesús Fuente)

973 Crónica del rey Juan II de Castilla. Minoría y primeros años de reinado (I406I420). Garcia, Michel (edición y estudio) (Víctor MuÑoz Gómez)

981 Da Silva, Marcelo Cândido, História Medieval (Diego Carlo Améndolla SPÍNOLA)

987 Galende Díaz, Juan Carlos y Ávila SeoAne, Nicolás, El rodado regio hispánico. Fernando III de León y Castilla (I23O-I252) (MAURicio Herrero JIMÉNEZ)

989 GARcía IzQuiERdo, Iván, Frontera, fuero y concejos. El valle del Riaza en la Edad Media (siglos VIII-XII) (CARLOS BARQUERO GOÑI)

993 García IzQuierdo, Iván y Peterson, David (coords.), Camino y Señorío. Obra selecta de Luis Martínez García (Enrique Cantera Montenegro) 
995 González Paz, Carlos Andrés, O Bispado de Mondoñedo na Idade Media. Territorio, comunidade e poder (ENRIQue CANTERA Montenegro)

997 López Martínez, Amalia, Minutarios notariales de Estevo Pérez (Ourense, siglo XIV) (José Miguel López Villalba)

999 Miranda García, Fermín y López de Guereño Sanz, María Teresa (eds.), La muerte de los príncipes en la Edad Media. Balance y perspectivas historiográficas (ANA Echevarría Arsuaga)

1003 Motis Dolader, Miguel Ángel, Vivencias, emociones y perfiles femeninos. Judeoconversas e Inquisición en Aragón en el siglo XV (ANA EcheVARRía ArSUAGA)

1007 Solórzano Telechea, Jesús Ángel y Martín Pérez, Fernando (coords.), Rutas de comunicación marítima y terrestre en los reinos hispánicos durante la Baja Edad Media. Movilidad, conectividad y gobernanza (ENRIQUe José Ruiz Pilares)

1013 Torre, Sandra de la - Etxeberria, Ekaitz - Díaz de Durana, José Ramón (coords.), Valer más en la tierra. Poder, violencia y linaje en el País Vasco bajomedieval (EnRIQue CANTERA Montenegro)

1015 TRIllo SAN José, Carmen, La Vega de Granada a partir de documentación árabe romanceada inédita (I457-I494). Estudio, edición e índices (INMACULADA GONZÁlez SopeÑA)

1019 Val Valdivieso, M. ${ }^{a}$ Isabel - Villanueva Zubizarreta, Olatz (Coords.), Pero Ansúrez. El conde, su época y su memoria (Enrique CANTERA Montenegro)

1021 Villanueva Morte, Concepción y Fernández de Córdova Miralles, Álvaro, El embajador Claver. Diplomacia y conflicto en las «Guerras de Italia» (I495-I504) (ENRIQUe CANTERA MONTENEGRO)

1023 Normas de publicación · Authors Guidelines 


\section{ARTÍCULOS · ARTICLES}

\section{VOLUMEN I}





\title{
CUATRO CERÁMICAS CON EPIGRAFÍA ÁRABE DEL MUSEU DE BORRIANA
}

\section{FOUR CERAMIC PIECES WITH ARABIC INSCRIPTIONS IN THE ARCHEOLOGICAL MUSEUM OF BORRIANA}

\author{
Carmen Barceló, Ana Labarta², Josep Benedito³ \& José Manuel Melchor ${ }^{4}$ \\ Recepción: 2020/01/14 · Comunicación de observaciones de evaluadores: 2020/06/05 · \\ Aceptación: 2020/09/08 \\ DOI: https://dx.doi.org/10.5944/etfiii.34.2021.26385
}

\section{Resumen}

En este trabajo se da a conocer una muestra de las más destacadas cerámicas de época almohade que se conservan en el Museo Arqueológico de Borriana y que proceden de excavaciones arqueológicas realizadas en la ciudad y su entorno. Se presta especial atención a la decoración epigráfica pintada o incisa sobre la arcilla fresca y la estampillada. Del análisis de su decoración epigráfica se ha extraído información de notable interés que complementa aquella directamente derivada del análisis tipológico.

\section{Palabras clave}

Cerámicas almohades; decoración; estampilla; esgrafiado.

\begin{abstract}
This paper will present a sample of the most outstanding Almohad ceramics that are preserved in the Archaeological Museum of Borriana. These pieces have been found during the archaeological excavations that were carried out in the city and its surroundings. Special attention has been paid to the calligraphic decoration painted or engraved on the clay, as well as to epigraphic stamps. The analysis of the epigraphic decoration on these ceramic pieces have produced results that are complementary to those obtained from the typological analysis.
\end{abstract}

Keywords

Almohad Ceramics; Ornamentation; Stamps; Sgraffito.

\footnotetext{
1. Universitat de València. C.e.: carme.barcelo@uv.es

2. Universitat de València. C.e.: ana.labarta@uv.es

3. Universitat Jaume I. C.e.: josep.benedito@uji.es

4. Museu Arqueològic Municipal de Borriana. C.e.: arqueologo@burriana.es
} 


\section{INTRODUCCIÓN}

Si bien la presencia almohade en al-Andalus comienza en II45, se sabe que este imperio norteafricano no conseguirá el dominio sobre el Levante peninsular hasta la rendición de los familiares de Ibn Mardanī̌ en II76. No conocemos la fecha de la conquista almohade de Borriana, aunque han quedado referencias a la llegada de los almohades a Valencia en II $\mathrm{I}^{5}$.

Los adornos caligráficos que pueden verse en las cerámicas de este periodo están dentro de bandas o cartelas y el tipo de escritura que utilizan puede ser tanto cúfico como cursivo de estilo tult. Algunas de las expresiones que contienen coinciden con las que ya figuraban en zócalos de viviendas de las alcazabas de Málaga y Granada del siglo xıl, tanto grabadas en mármol como pintadas con almagra, del tipo «bendición completa, gracia amplia, suerte, salud, felicidad, alegría, fortuna, gloria, apoyo, honra, poder y prosperidad para su dueño» (baraka kāmila wa-ni'ma šāmila wa-gibța wa-salāma wa-sa'āda wa-surūr wa-yumn wa-'izz wa-ta'yìd wa-šaraf wa-tamkin wa-iqbāl li-șăhibi-hi $)^{6}$. Varias de estas voces eran frecuentes ya en la obra de tierra de etapas anteriores; con los almohades continuó su uso, solas o combinadas con adjetivos, como «el poder, el poder pertenece a Dios, bendición completa» (al-mulk, al-mulk li-llāh, baraka kāmila) mientras que otras son nuevas, propias de esta época; las más repetidas son «la gloria, la gloria pertenece a Dios, salud, gloria permanente y fortuna duradera» (al- 'izz, al- 'izza li-llāh, salāma, al- 'izz al-qā’im wa-l-yumn al-dāìm)' .

Hasta ahora, la interpretación de los textos presentes en las de datación posterior al califato omeya apenas si ha merecido la atención de los especialistas. Para su lectura, no se suele recurrir a expertos, sino que se consulta a cualquiera que haya realizado algún curso de lengua árabe o tenga cierta práctica en la identificación de monedas, en la mayor parte de los casos sin experiencia en epigrafía árabe sobre otro tipo de material. Como resultado, los catálogos de exposiciones, fichas de museos, trabajos de arqueología y memorias de excavación han publicado interpretaciones que se alejan de la realidad de las leyendas que figuran en las piezas. Esas lecturas erróneas sirven luego de base, comparación y referencia para las siguientes y así los errores se propagan y consolidan.

Por todo ello señalamos que se deberá proceder a una profunda revisión de lo conservado y a la lectura de sus inscripciones antes de que se puedan establecer los periodos históricos en que se utilizan determinadas expresiones. Otra tarea necesaria consistirá en relacionar la lista de términos que figuran en las de cada

5. Huici Miranda, Ambrosio: Historia musulmana de Valenciay su región. Valencia, Ayuntamiento, 1970, III, p. 167-168.

6. OCAÑA JimÉnEZ, Manuel: «Zócalos hispanomusulmanes del siglo XII», Al-Andalus, 10/1 (1945), pp. 164-169, en especial pp. 168-169 texto y traducción y lám. 15-18.

7. BARCeló, Carmen: «Epigrafía árabe en cerámica», en LeRma AlegriA, Josep Vicent (com.): L’Argila de la mitja Iluna. La ceràmica islàmica a la ciutat de València. 35 anys d'arqueologia urbana. València, Ajuntament, 2018, pp. 233-266; cf. pp. 249-259. 
tipo con las técnicas ornamentales utilizadas por los artesanos para plasmarlos. De ese modo se podrá decidir si hubo una relación efectiva entre expresiones y técnicas, no solo desde el punto de vista cronológico sino también decorativo (pintado, cuerda seca, esgrafiado, estampillado, aplicado en relieve...). Al igual que habrá que ver si hay relación directa entre los términos inscritos y las formas de los recipientes que los ostentan.

Está claro que lo anterior requiere una labor ingente, imposible de realizar aquí, donde nos limitaremos a comentar cuatro objetos destacados de cronología almohade, conservados en el Museo de Borriana, que hemos estudiado a través de las fotografías que nos ha proporcionado dicha institución.

Estos recipientes han sido hallados en la ciudad de Borriana, de la que apenas se tienen noticias por documentos históricos del periodo islámico. Los textos árabes y ciertas referencias cristianas contemporáneas a la conquista apenas permiten vislumbrar cómo se organizaba la administración de esta parte de la costa levantina, emplazada en un espacio caracterizado por la presencia de otras ciudades importantes como Murbātir (Sagunto) y Unda (Onda). Sabemos que lindaba con el territorio de Murbātir por el sur, mientras que lo hacía con Unda por el oeste; al este limita con el mar Mediterráneo, pero no se han encontrado referencias históricas sobre el límite norte.

Al-Rāzī ${ }^{8}$, que vivió en la primera mitad del siglo X, cita el distrito o término de Borriana. Al-Idrīsi $\bar{i}^{9}$ hace lo propio en el siglo xıı y describe también su puerto (marsà Buryāna). En las donaciones del rey Jaime I hay de nuevo referencias sobre el puerto (ad portum maris Burriane) ${ }^{\mathrm{I}}$. Ibn al-Abbār (m. I260) al tratar de un personaje muerto en el siglo xII, se refiere a ella como centro de un 'amal ${ }^{\text {II }}$. El geógrafo árabe al-Himyarīin (m. I325), que utiliza textos andalusíes anteriores a su tiempo, señala que «es una ciudad magnífica, poblada, con abundantes frutos, árboles y viñas». Por otra parte, se ha constatado una ocupación general del entorno rural alrededor de la madina, como evidencian los testimonios arqueológicos y también los textos. Está bien atestiguada la existencia de alquerías musulmanas y la documentación de época cristiana completa la información que tenemos sobre la organización de este tipo de poblamiento diseminado. Entre los textos destaca el Llibre del

8. LÉvi Provençal, E.: «La description de l'Espagne d'Ahmad al-Râzî. Essai de reconstitution de l'original arabe et traduction française», Al-Andalus, XVIII (1953), pp. 51-108, § 21 p. 72. Crónica del moro Rasis. Edición D. Catalán y S. de Andrés, Madrid, 1975, p. 38.

9. Edrîsî. Description de l'Afrique et de l'Espagne. Edición y traducción R. Dozy et M. J. de Goeje, Leiden, Brill, 1866 reimpresión anastática 1968, pp. 175 y 191. AL-IDRīsī. Los caminos de al-Andalus en el siglo XII. Edición y traducción J.A Mizal. Madrid, CsIC, 1989, pp. 159-161.

10. De María, Ramón: El repartiment de Burriana y Villarreal. Vila-real, Caja Rural Católico-Agraria S. Coop. de Crédito, Ltda., 1933, p. 28. cf. p. 71 .

11. GUICHARD, Pierre: «Los orígenes islámicos», en Burriana en su historia I. Burriana, Ajuntament, 1987, pp. 71-87;

12. Labarta, Ana; Barceló, Carmen; Veglison, Josefina: València àrab en prosa i vers. València, Publicacions de la Universitat de València, 2011, $\S 8$ y 9 p. 64. 
Repartiment $^{13}$, la principal fuente contemporánea para estudiar la repoblación de las tierras valencianas a partir de Jaime $\mathrm{I}$.

Las fuentes cristianas tampoco mencionan la extensión de su término; la referencia más antigua está en el Cantar del Mio Cid $^{14}$. Con la caída de Tortosa, en el año II48, se convirtió en cabeza de circunscripción militar, tal y como se lee en un texto del Archivo de la Corona de Aragón, de la época de Ramón Berenguer Iv, que cita a un alcaid o jefe militar de Borriana ${ }^{15}$. La conquista cristiana se produjo en I233 y la Carta-Pobla se le concedió tres meses después, en noviembre, aunque apenas dos años más tarde se hizo necesario redactar una segunda ${ }^{\mathrm{I} 6}$. Entre los documentos de donaciones de Jaime I se han encontrado referencias sobre «Castillione Burrianae» ${ }^{17}$, «Castelló del camp de Borriana» (Castellón), Nules y Almazora ${ }^{18}$, que habrían pertenecido a su antiguo distrito, y datos concretos sobre la fundación de Vila-real ${ }^{19}$, que fue segregada del antiguo término municipal de Borriana con buena parte de su zona occidental.

\section{LA CERÁMICA ALMOHADE EN BORRIANA}

A lo largo de los últimos años, la investigación arqueológica ha ido descubriendo piezas cuyo estudio ha permitido que conozcamos hoy su difusión mejor que hace unas décadas. En las excavaciones que se han llevado a cabo en la localidad de Borriana no se han documentado hornos pero en cambio sí objetos elaborados con la técnica del bizcochado, vasijas de usos domésticos y culinarios como ollas y cazuelas, fuentes y ataifores, vajilla de mesa, de presentación y consumo, redomas, formas de preparación de alimentos como marmitas, que solían ser usadas sobre un anafre, jarritas y jarritos, tapaderas, tinajas, orzas, candiles, lámparas y arcaduces, lebrillos y trípodes. También se ha registrado loza estannífera decorada con trazos negros; loza azul turquesa y cerámicas decoradas con trazos verdes y otras con trazos verdes y negros; vidriada con esmalte de plomo translúcido y otra con vidriado teñido de verde.

Además han salido a la luz en las excavaciones productos procedentes de talleres más cualificados, ricamente decorados con cuerda seca parcial, pintados de

13. Llibre del repartiment del Regne de Valencia. Edición, estudio preliminar e índices M. ${ }^{a} \mathrm{D}$. Cabanes Pecourt y R. Ferrer Navarro, 2 vols. Zaragoza, Anúbar, 1979.

14. GUICHARD, Pierre: op. cit. p. 71.

15. Guichard, Pierre: op. cit. p. 71 y 87 nota 5. Guichard, Pierre: Al-Andalus frente a la conquista cristiana: los musulmanes de Valencia, siglos XI-XIII. Valencia, Universitat de València, 2001, pp. 243-244 y nota 17.

16. García, Vicent: Llibre de privilegis de Borriana (1233-1350). Burriana, Col-lecció Papers 14, 1989, pp. 14 y 33.

17. RAMÓN FERNÁNDEZ, Francisca: El ingreso en la comunidad de pescadores de El Palmar y la transmisión hereditaria del «redolí». Valencia, Publicacions de la Universitat de València, 2001, p. 95.

18. De María, Ramón: op. cit. p. 253, 70 y 120 respectivamente.

19. De María, Ramón: op. cit. p. 253. 
manganeso y/o esgrafiados ${ }^{20}$. A la vez que se incorporaron estas técnicas sofisticadas, se amplió el repertorio formal conocido en la ciudad, incluyendo originales jarritas, fuentes, bacines, cántaros, braseros, alcadafes, candiles y tapaderas, que aparecían profusamente ornamentadas.

Entre todas ellas se ha encontrado un grupo muy interesante con características plenamente almohades, periodo en el que, como se ha comentado en numerosas publicaciones $^{21}$, se observa un gran desarrollo de la producción, que se ha traducido en una mayor cantidad de sus hallazgos en las excavaciones de la ciudad.

Tres de los ejemplares que estudiamos aquí han salido a la luz en las intervenciones arqueológicas realizadas en el centro de la ciudad, en los solares de la Nueva Casa Abadía y en la calle Mayor núm. 26 esquina con la calle Forn de la Vila; el cuarto fragmento procede del yacimiento de El Palau. Todos ellos se hallan depositados en los fondos del Museo Arqueológico de la localidad. Su estudio se ha centrado en los aspectos formales, decorativos y técnicos.

El conjunto cerámico que procede de la excavación de la calle Mayor está formado por jarras, jarritas, botellas con pitorro vertedor, tazas, cazuelas y ollas, tapaderas, ataifores vidriados y pintados con chorreones de manganeso, braseros con pared gallonada, anafres o fogones con parrilla cupular y una larga lista que muestra la diversidad de la vajilla y menaje usados en esa época. Se fechan hacia finales del siglo xıI y primera mitad del xıII y se trata de un grupo de características plenamente almohades.

Las piezas sin vidriar, simplemente bizcochadas o juagueteadas, son las más frecuentes en este lote, pero junto a las realizadas a torneta y otras con un torneado rápido y poco cuidado, existen otras formas como las jarritas de paredes finas y algunos ataifores sin vidriar que manifiestan una alta calidad técnica. Las de cocina están elaboradas con una arcilla refractaria. En la pintada sobre bizcocho, los colores utilizados son negro o rojo aplicados con pincel o con los dedos. Esta decoración está relegada a las de uso cotidiano vinculadas al transporte y almacenamiento de agua y a algunos tipos de ollas.

20. Claramonte, Mónica y Benedito, Josep: «La cerámica hispanomusulmana y mudéjar», La arqueología de la Buriyyana islámica a la Borriana cristiana, Burriana, Ayuntamiento, 2011, pp. 103-124.

21. Azuar, Rafael et alii: «Cerámica tardo-andalusí del País Valenciano (Primera mitad del siglo XIII)》, Actes du sème Colloque sur la Céramique Médiévale (Rabat 11-17 Novembre 1991), Rabat, Institut National des Sciences de l'Archéologie et du Patrimoine, 1995, pp. 140-161; ACIÉN ALMANSA, Manuel: «Cerámica y propaganda en época almohade», Arqueologia medieval, 4 (1996), pp. 183-191; LeRMA ALEGRIA, Josep Vicent: «Relaciones mediterráneas de la Valencia islámica: las cerámicas importadas», Les Illes Orientals d'Al-Andalus i les seues relacions amb Sharq Al-Andalus, Magrib i Europa cristiana, actas de V Jornades d'Estudis Històrics Locals, Palma, 1987, pp. 339-358; Álvaro ZAmorA, María Isabel: «La cerámica andalusí», Artigrama, 22 (2007), pp. 337-369; COLL CONESA, Jaume: «Ceràmica i canvi cultural a la València medieval. L'Impacte de la Conquesta», Afers, 7 (1989), pp. 125-167; COLL CONESA, Jaume: «La ceràmica valenciana del segles XIII al XIX. Tècniques i processos de la producció. Visió diacrònica de conjunt», en PADILLA, Josep I. y VILA, Josep M. (coords.): Ceràmica Medieval i Postmedieval. Circuits productius i seqüencies culturals. Barcelona, Universitat de Barcelona, 1998, pp. 165-176; COLL CONESA, Jaume: La cerámica valenciana (apuntes para una síntesis). Valencia, Asociación Valenciana de Cerámica, 2009; COLL CONESA, Jaume y GARCíA PORRAS, Alberto: «Tipología, cronología y producción de los hornos cerámicos en al-Andalus», Albisola, XLII (2010), pp. 7-24; COLL, Jaume; PASCUAL, Josefa y MARTÍ, Javier: Cerámica y cambio cultural. El tránsito de la Valencia islámica a la cristiana. Madrid, Dirección General de Bellas Artes y Archivos, 1989. 
Los motivos incisos están realizados mediante una punta, fina, o a cuchillo; se encuentran solos o acompañados de incisión más profunda o estampillado. Suele tratarse de bandas onduladas, incisiones múltiples y sogueados que se emplean para delimitar o rellenar espacios en piezas adornadas con otras técnicas.

Para lograr los motivos impresos se utiliza la técnica del estampillado mediante cuños rectangulares o circulares con la decoración grabada en hueco y en negativo.

En algunos casos se aplica arcilla sobre la vasija para formar cordones, cordoncitos o bandas que sobresalen de la pared del recipiente. La cuerda seca parcial, combinada muchas veces con el esgrafiado, se utiliza para plasmar motivos decorativos vegetales, geométricos o epigráficos; en esta técnica el vidriado no cubre completamente la arcilla, sino que la deja ver en algunas zonas.

Los objetos que estudiamos constituyen uno de los conjuntos almohades más interesantes hallados en el antiguo territorio de la Borriana islámica. Hay que subrayar el excelente estado de conservación de este material; presenta una buena manufactura y un repertorio formal y decorativo muy rico. Se observa un perfecto torneado en los jarritos, así como en las jarritas, cuya calidad decorativa se aumenta con el esgrafiado sobre manganeso, con decoraciones en las que son frecuentes complejos temas geométricos o/y epigráficos, e incluso incorporando la cuerda seca.

\section{EPIGRAFÍA ÁRABE CON TÉCNICA ESGRAFIADA}

Como se verá, dos de los ejemplares que comentamos a continuación son jarritas de pasta clara de tonalidad ocre-blancuzca que, tras haber sido cubiertas con una ligera capa de manganeso, se adornaron con la técnica del esgrafiado. Este tipo de decoración tuvo una cronología limitada y su área de producción se circunscribe a un espacio concreto de las tierras levantinas, desde donde se comercializaría. El mayor número de ejemplares realizados con esta técnica se ha encontrado en el área de Murcia (Murcia, Lorca, Cartagena, Cieza), Valencia capital, Alicante (Jijona, Denia, Alcoy) y Mallorca. Desde los centros productores se llevarían por mar a otras zonas de dominio musulmán del litoral peninsular (Castellón de la Plana, Sagunto, Cádiz) y norteafricano (Ceuta, Tetuán, Tanger, Lixus, Salé, Bugía). Se han localizado fragmentos sueltos en Silves y Mértola (Portugal) pero son raros los hallazgos en puntos del interior peninsular ${ }^{22}$. La cronología que tradicionalmente

22. Navarro PALAzón, Julio: «Hacia una sistematización de la cerámica esgrafiada». /l Coloquio Internacional de Cerámica Medieval en el Mediterráneo Occidental, Madrid, Ministerio de Cultura, 1986, muestra en el mapa 1 los lugares en que se habían producido hallazgos hasta 1985; en p. 167 da bibliografía sobre los de la zona levantina; en p. 169 sobre los norteafricanos. CRESPO PASCUAL Almudena: «Cerámica esgrafiada: estado de la cuestión», Anales de Arqueología Cordobesa, 12 (2001), pp. 353-370 añade en p. 353 bibliografía hasta 2000 sobre Portugal y el interior peninsular. Se completará con Gómez MARTínez, Susana: La cerámica islámica de Mértola producción y comercio, (Tesis Doctoral inédita), Universidad Complutense de Madrid, 2004. Más información de estos hallazgos en: GUILLERMO MARTínEz, 
se ha propuesto para la producción esgrafiada ${ }^{23}$ va desde principios del periodo almohade (II47) hasta, al parecer, la conquista cristiana de cada zona, que en general tuvo lugar en la primera mitad del siglo XIII (Mallorca I229, Borriana I233, Valencia I238, Murcia I243 y I266). Con todo, sabemos que en Murcia y Valencia el esgrafiado se prolonga en época mudéjar, durante algunos años, en una fase caracterizada por el empobrecimiento de las series ornamentales, reducidas a formas geométricas sencillas ${ }^{24}$.

Se suelen emplear como motivo decorativo en la epigrafía esgrafiada las expresiones coránicas al- 'izz, al- 'izza, al- 'izza li-llāh, escritas en estilo cursivo y en un cúfico específico característico de la metalistería oriental de esta misma época, llamado por los especialistas «cúfico parlante»; otra de las voces, presente ya en el siglo xII, es la palabra salāma, con y sin artículo; también se hallan «gratitud», «éxito», «aguada pura», «aguada suficiente» (̌̌ukr, tawfīq, sāqiya șāfiya, sāqiya $k a ̄ f i y a)^{25}$. A título de ejemplo puede compararse la producción de un alfar almeriense $^{26}$; en las piezas allí estudiadas se ven los vocablos al-saläma, al-yumn, yumn, baraka, baraka kāmila y al-tawfīq.

Martín: Cartagena medieval. Cartagena, Cuadernos Monográficos del Museo del Teatro Romano, 2014, p. 48 y lám. VI, p. 47. Navarro, Julio y JImÉNez, Pedro: «La cerámica andalusí de Siyâsa: estudio preliminar», Cerâmica Medieval e

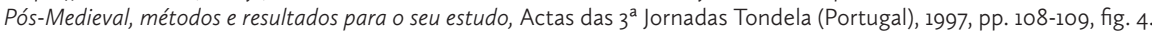
HITA, José Manuel y VILLADA, Fernando: «Producción y comercialización de la cerámica esgrafiada y pintada en el ámbito de El Estrecho de Gibraltar. El caso de Ceuta», Almoraima, 42 (2011), pp. 215-238. ATAALLAH, Mohamed: «Céramiques musulmanes à paroi fine incisée ou peinte de Lixus», Bulletin d'Archéologie Marocaine, 7 (1967), p. 630 y fig. 1. BAzzANA, André y MONTMESSIN, Yves: «Quelques aspects de la céramique médiévale du Maroc du Nord: problèmes typologiques et chronologiques», Actes du $5^{\text {ème }}$ Colloque sur la Céramique Médiévale (Rabat 11-17 Novembre 1991), Rabat, Institut National des Sciences de l'Archéologie et du Patrimoine, 1995, pp. 241-259. COLL, Jaume y MARTínEZ, Virgilio: «La ocupación medieval», Lixus-2 ladera sur. Excavaciones arqueológicas marroco-españolas en la colonia fenicia. Campañas 2000-2003. Saguntum extra 6 (2005), p. 54, 60. DeLPY, Alexandre: «Note sur quelques vestiges de céramique recueillis à Salé», Hespéris. Archives Berbères et bulletin de l'institut des hautes études marocaines, 42 (1955), p. 139. MARÇAIs, Georges: Les poteries et faïences de Bougie (collection Debruge). Contribution a l'étude de la céramique musulmane, Constantine, Braham, 1916, pp. 25-26. Jenkins-MadinA, Marilyn : Medieval Maghribî Ceramics. A Reappraisal of the Pottery Production of the Western Regions of the Muslim World. New York, New York University, 1979, p. 136, 152. Gomes, Rosa Varela: «Cerâmicas muçulmanas do Castelo de Silves», XELB: revista de arqueologia, arte, etnologia e história, 1 (1988), p. 262. GomES, Rosa Varela y Gomes, Mário Varela: Palácio Almoada da Alcáçova de Silves. Lisboa, Museo Nacional de Arqueologia, 2001. Gómez Martínez, Susana: «El arrabal portuario de Mértola (Portugal): el registro cerámico andalusí», revista Onoba, 4 (2016), p. 191. FernÁNDEZ, Alejandro; MARTín, Miguel Á. y MoredA, Javier: «Excavaciones arqueológicas en el monasterio de San Benito el Real de Valladolid. Un interesante fragmento de cerámica esgrafiada y cuerda seca parcial», Boletín de Arqueología Medieval, 3 (1989), pp. 233-241; Coll, Jaume; HuÉLAMO, José María y SoliAs, José María: «Avance de un estudio sobre los restos materiales del castillo islámico de Cuenca», Actas I Congreso de Arqueología Medieval Española, III, Huesca, 1989, pp. 77-97.

23. Navarro Palazón, Julio: La cerámica esgrafiada andalusí de Murcia. Madrid, Casa de Velázquez, 1986. Navarro Palazón, Julio: La cerámica islámica en Murcia. Vol. I. Catálogo. Murcia, Ayuntamiento, 1986. Navarro Palazón, Julio: «Hacia una sistematización ...», pp.165-178.

24. Navarro Palazón, Julio y Jiménez Castillo, Pedro: «La cerámica andalusí de Murcia a la llegada de Alfonso X», Alfonso x y su época. Catálogo de la exposición celebrada en Murcia. Murcia, 2009, p. 700; AmIGUes, François; Mesquida, Mercedes y Soler, M. ${ }^{a}$ Paz: «La cerámica esgrafiada en los talleres mudéjares de Paterna (Valencia)», Actas Congreso A Cerámica Medieval no Mediterrâneo Ocidental, Mértola, 1991, p. 305, Lám. 1-5.

25. BARCELó, Carmen: «La epigrafía ornamental», La cerámica islámica en la ciudad de Valencia II. Estudios, Valencia, Ayuntamiento, 1990, p. 141.

26. Flores Escobosa, Isabel; Muñoz Martín, María del Mar; Lirola Delgado, Jorge: «Las producciones de un alfar islámico en Almería», Arqueología y Territorio Medieval, 6 (1999), pp. 207-239. 
El esgrafiado se combina a veces con pintura de manganeso sobre fondo blanco y también con verdugones de esmalte, por lo general de color azul turquesa.

\subsection{JARRITA CON DOS ASAS HALLADA EN LA NUEVA CASA ABADÍA}

Fue encontrada en las excavaciones de la nueva Casa Abadía de Borriana. Dicha intervención arqueológica, realizada en el año 2009, aportó interesantes novedades para el conocimiento del periodo almohade en la ciudad, en concreto se documentaron niveles andalusíes asociados a un tramo de la muralla y a una vivienda, en la que se identificaron los restos de un patio y varias habitaciones ${ }^{27}$. La jarrita, destinada al servicio del agua, destaca por su calidad artística (Figura 1).

Tiene cuerpo de tendencia globular, pie anular pequeño y dos asitas afrontadas. El borde sigue la dirección de la pared, con labio apuntado y cuello alto troncocónico invertido. Se ha elaborado con pasta clara de tonalidad ocre-blancuzca. Dimensiones: diámetro del borde de $7 \mathrm{~cm}$, diámetro de la base de $4 \mathrm{~cm}$, altura de $14,2 \mathrm{~cm}$.
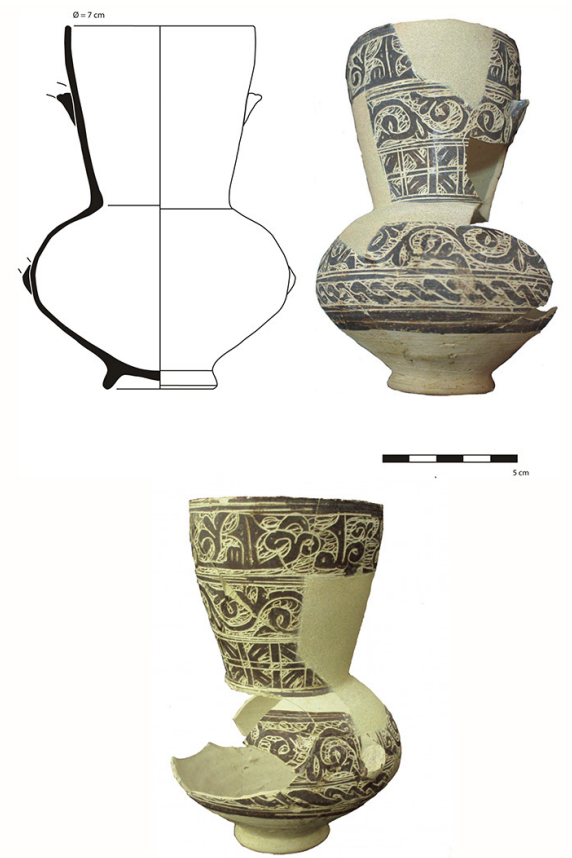

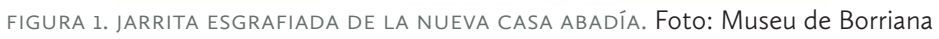

27. Melchor Monserrat, Jose Manuel: «La arqueología como fuente de estudio para la Burriana medieval», La arqueología de la Buriyyana islámica a la Borriana cristiana. Burriana, Ayuntamiento, 2011, pp. 11-48. 
Está pintada y esgrafiada, imitando el efecto de los trabajos en metal; presenta cinco franjas decorativas, tres en el cuello y dos en el cuerpo inferior. Las dos franjas con ataurique están cortadas por la implantación de las asas; solo la que se halla junto a la boca es epigráfica y no queda interrumpida por el arranque de las asas. Además lleva una línea de escritura pintada en la parte interior del cuello, cerca del borde.

Los adornos no epigráficos del cuello consisten en una retícula formada por cuadrados con hojas en sus diagonales y divisiones en cruz, un motivo del que apreciamos un claro paralelo en una jarrita hallada en el Castillico del Paraíso (Cehegín) ${ }^{28}$. Sobre dicha retícula hay otra banda con decoración de roleos, muy similares o iguales a los que se ven en buen número de jarritas descubiertas en Lorca y Murcia, similares a esta ${ }^{29}$.

La franja epigráfica exterior se sitúa en una banda que corre alrededor de la boca de la vasija; las letras son negras y dicen dos veces al-saläma 'el bienestar' (Figura 2). El estilo de letra cúfica corresponde a un tipo que empieza a verse a mediados del siglo Xı bajo dominio almohade; presenta sus rasgos característicos: en los ápices de la parte superior de las letras altas, del nexo läm-alif y de la tā' marbūța hay un engrosamiento triangular, con el centro hueco. Entre el final de la palabra repetida y el principio de la otra tiene los adornos vegetales particulares de este periodo. El mismo término árabe, con una epigrafía cúfica coetánea, se ve en la jarrita con dos asas, pintada y esgrafiada, que apareció en las excavaciones de l'Almoina de Valencia, donde estuvo ubicado el alcázar de los gobernadores (SIAM I/713) ${ }^{30}$. La misma palabra al-salāma, pero en grafía cursiva, se ve en un fragmento de panza de jarrita hallado en la ciudad de Murcia $^{3 \mathrm{I}}$.

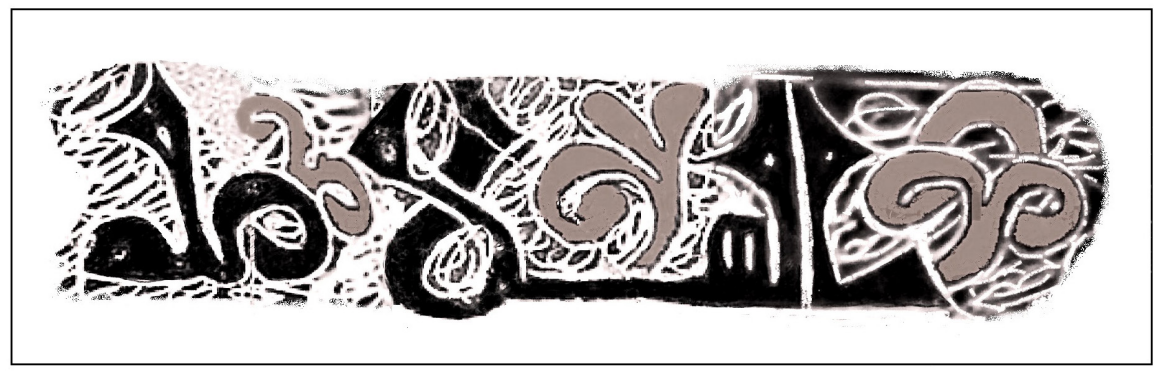

FIGURA 2. JARRITA DE LA NUEVA CASA ABAdíA. FRANJA EPIGRÁFICA EXTERIOR CON AL-SALĀMA. Dibujo: Carmen Barceló

28. Navarro Palazón, Julio: «Hacia una sistematización...», p. 165, lám. 1 y p. 175, lám. 5.

29. Navarro PALAZÓN, Julio: «Hacia una sistematización...», passim.

30. Lerma Alegria, Josep Vicent (com.): L'Argila de la mitja lluna. La ceràmica islàmica a la ciutat de València. 35 anys d'arqueologia urbana. València, Ajuntament, 2018, p. 256.

31. Navarro Palazón, Julio: «Hacia una sistematización...», p. 169, lám. 2 c. 
Ya en I986, al estudiar la cerámica esgrafiada, Navarro Palazón señaló «la frecuente aparición de grafías en el interior de los cuellos, hecho que por ahora sólo se ha documentado en vasos de pequeñas dimensiones, normalmente jarritas ${ }^{32}$. También indicaba que hasta ese momento no había sido posible obtener lectura alguna. En efecto, se ven signos en el interior de las bocas en muchos de los recipientes esgrafiados publicados ${ }^{33}$.

La inscripción del interior de nuestra jarrita repite tres veces la misma palabra, separada por dos trazos verticales, en letra cúfica pintada, con la particularidad de que utiliza un tipo de caligrafía en la que no hay línea base de escritura ni se dibujan los apéndices inferiores de las letras. En este caso el término que se oculta en los trazos del diseño parece ser al-yumn 'la fortuna' (Figura 3).

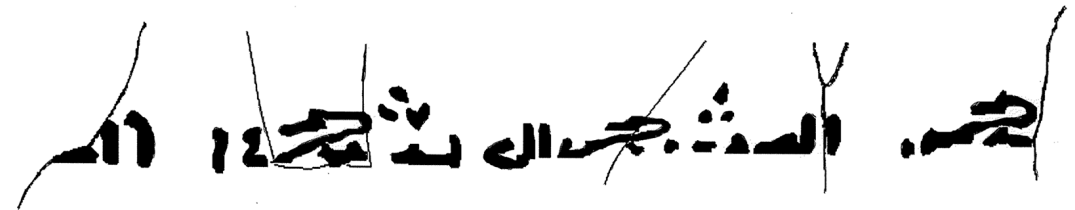

FIGURA 3. JARRITA DE LA NUEVA CASA ABADÍA. FRANJA EPIGRÁFICA DEL INTERIOR DEL CUELLO REPITIENDO AL-YUMN. Dibujo: Carmen Barceló

Se advierte claramente el cuello de cisne de nün final y los tres puntos centrales representan el trifolio que desde época omeya corona la letra mìm en posición medial ${ }^{34}$. El trazo que se observa en el interior de esta jarrita deriva de un motivo típico de la zona levantina, que se pinta con adornos característicos. Similares grafías cúficas de la misma palabra pueden verse en motivos decorativos pintados en objetos de los siglos $\mathrm{x}-\mathrm{XII1}{ }^{35}$.

La voz «fortuna» se documenta en al-Andalus desde finales del siglo xı hasta el xill sobre numerosos objetos. En alfarería se ha realizado con todo tipo de técnicas (verde-manganeso, negro sobre blanco, en reflejo metálico, etc.) ${ }^{36}$; en

32. Navarro Palazón, Julio: «Hacia una sistematización...», p. 177.

33. Navarro Palazón, Julio: «Hacia una sistematización...», p. 167 figura 1, Lorca; p. 168 figs. 2 y 3. Lorca y Murcia. BAzZANA, Andrés et alii: La cerámica islámica en la ciudad de Valencia [1]. Catálogo. Valencia, Ayuntamiento, 1983, p. 143, $n^{\circ}$ 1043; p. 145, n 823, Valencia. La pieza de p. 147, n 822 está también en BARCELó, Carmen: «Epigrafía...» pp. 262263 y fig. 13. Ferrer Clarí, Agustín y Pelufo Pérez, M. a Ángeles: «Estudio de las cerámicas esgrafiadas de Al-Gezira Suqar», Al-Gezira. Revista d'Estudis Històrics-Ribera Alta, 4/5 (1988), pp. 47-73, figura p. 62.

34. BARCeló, Carmen: «El cúfico andalusí de 'provincias' durante el Califato (300-403/912-1013)», Cuadernos de Madinat al-Zahrâ', 5 (2004) [Actas de las Iv Jornadas de Madinat al-Zahrâ',: Nuevas investigaciones sobre el Califato de Córdoba], pp. 173-197; cf. p. 185.

35. Véanse los ejemplos del dibujo de C. Barceló en HEIDENREICH, Anja: Islamische Importkeramik des hohen Mittelalters auf der Iberischen Halbinsel. Madrid, Deutsches Archäeologisches Institut, 2007, p. 312.

36. A A BELLÁN, Juan et alii: «Cerámica hispano-musulmana de la provincia de Cadiz. Primeras piezas halladas en el yacimiento de Los Caños de Meca», "I Coloquio Internacional de Cerámica Medieval en el Mediterráneo Occidental, Madrid, Ministerio de Cultura, 1986, pp. 141-147. En p. 144, lám. 4, fig. 4 y p. 146 lám. 8 motivo al-yumn repetido en el interior de una jofaina de loza dorada (leído al-hamdu «alabanza»). Se encontró una pieza idéntica en la Presó de Sant Vicent de Valencia, cf. LERMA ALEGRIA, Josep Vicent (com.): L’Argila de la mitja lluna. La ceràmica islàmica a la ciutat de València. 35 anys d'arqueologia urbana. València, Ajuntament, 2018, p. 334, nº 118. 
el siglo xil y en estilo cursivo está sobre jarras y jarritas esgrafiadas, en las que a veces forma parte de la locución al-yumn wa-l-iqbāl; y en estampillas o con las letras sobrepuestas, en tinajas y grandes contenedores de agua.

Una decoración muy similar a la de la jarrita de Borriana se aprecia en el interior del cuello de ejemplares hallados en Almería, aunque en algunos casos la palabra está trazada de un modo más legible y fácilmente identificable; se da la circunstancia que varias de ellas también muestran al exterior la palabra al-saläma ${ }^{37}$. Sería conveniente que se hiciera un amplio inventario de todas estas inscripciones pintadas en el interior de los cuellos y se intentara relacionar los signos con las formas que las ostentan antes de intentar proponer una lectura y preguntarse cuál era su sentido.

Tras su estudio y la identificación de sus características tipológicas y decorativas, advertimos ciertas similitudes con la producción hallada en el área murciana, tanto a nivel formal como en su alta calidad artística; por ello proponemos vincular esta jarrita de Borriana con alguno de los centros alfareros de aquella zona ${ }^{38}$.

\subsection{JARRITA DE LA CALLE MAYOR 26}

Fue encontrada en las excavaciones de la calle Mayor núm. 26, esquina calle Forn de la Vila. En esta intervención se identificaron los restos de la muralla musulmana, junto a un cementerio y viviendas de la misma época ${ }^{39}$. En los rellenos de colmatación, tanto de las fosas como de los silos, salieron a la luz numerosas cerámicas almohades que deben ponerse en relación con las prácticas agrarias de la época.

Esta otra jarrita es un recipiente de calidad, destinado al servicio de agua (Figura 4). Tiene dos asas de bastante vuelo, que van de la mitad de la pared del cuerpo a la del cuello, y quizá repié anular, que no se conserva y que estaría separado del cuerpo por una moldura baja. La pasta es de textura bizcochada de color ocre-blancuzco con incrustaciones minerales. Dimensiones: diámetro del borde de $9 \mathrm{~cm}$; altura conservada de II,5 $\mathrm{cm}$.

La forma del borde es abierta, con labio biselado, cuello con un ligero éntasis y cuerpo carenado.

La parte superior está muy fragmentada e incompleta. En el cuello quedan restos parciales de una banda epigráfica, pintada en negro, dentro de dos cartelas

37. Flores Escobosa, Isabel; Muñoz Martín, María del Mar; Lirola Delgado, Jorge: op. cit. p. 224, figs. 1/1, $1 / 3$, p. 225 figs. $2 / 7,2 / 8$.

38. AzUAR RuIz, Rafael: «Alfares y Testares del Sharq Al-Andalus (siglos XII-XIII). Producción, tipología y distribución», en PADILLA, José I. y VILA, Josep M. (coords.), Ceràmica Medieval i Postmedieval. Circuits productius i seqüències culturals, Barcelona, Universitat de Barcelona, 1998, pp. 57-71. NAvArro PALAzón, Julio: La cerámica esgrafiada andalusí de Murcia. Madrid, Casa de Velázquez, 1986.

39. Melchor Monserrat, Jose Manuel: op. cit. 
que comienzan y acaban en las dos asas; están enmarcadas por bandas de roleos esgrafiados y verdugones de vedrío azul turquesa (Figura 5). Por ahora no hemos sabido descifrarla.
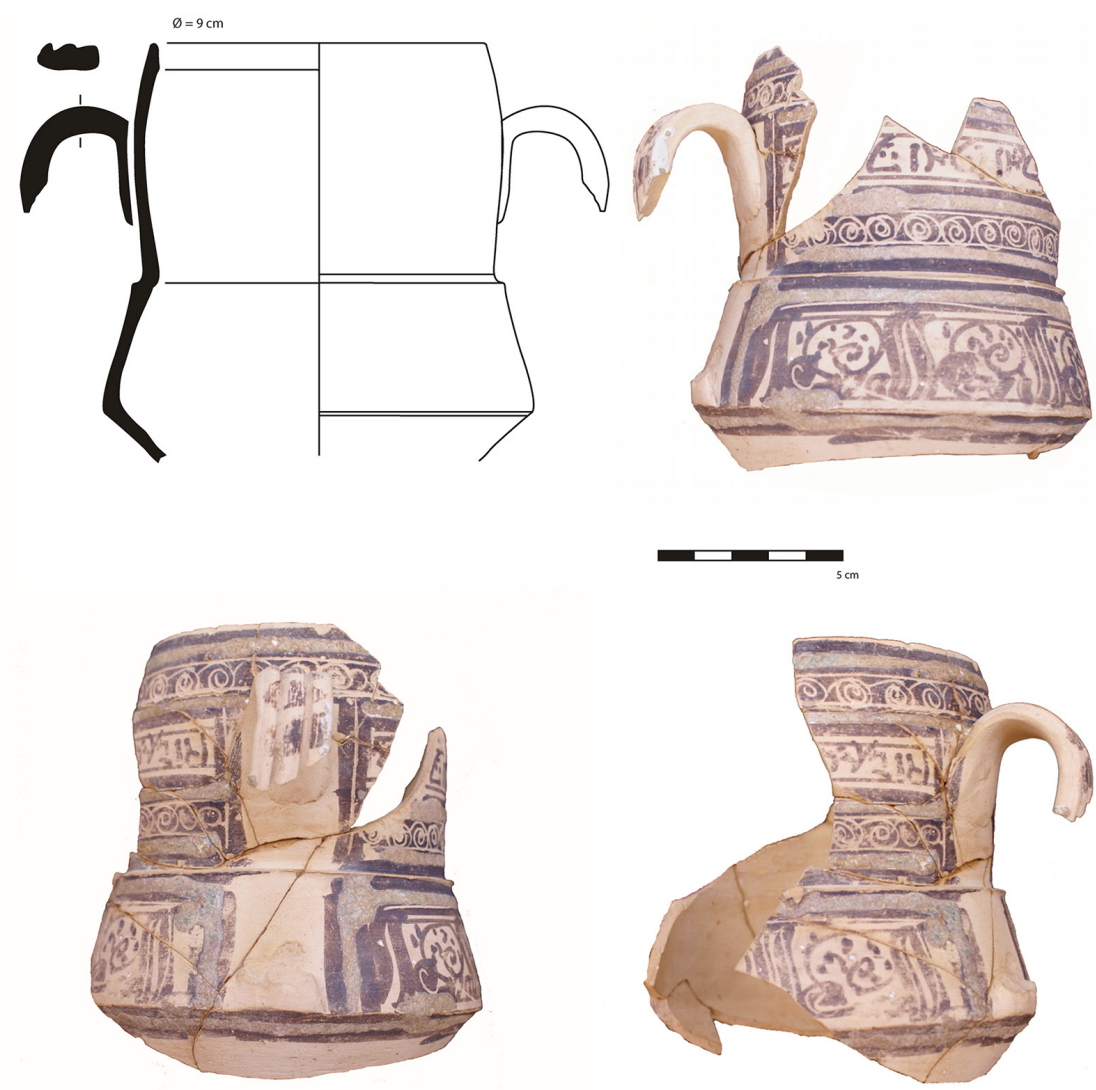

FIGURA 4. JARRITA DE LA CALLE MAYOR 26. Foto: Museu de Borriana

Su ornamentación es muy similar al cuello de jarrita encontrado en la calle Avellanas de Valencia (SıAm 823), que presenta idénticas cartelas pintadas entre roleos esgrafiados y líneas de vidriado. En este caso, la grafía está completa, es más legible y se comprueba que en cada cartela se repite tres veces el término al-salāma ${ }^{40}$. La del sıAm conserva en el interior, junto a la boca, tres letras en grafía cursiva. Tal vez también esta de Borriana llevara letras en el interior, en alguna de las zonas que se han perdido.

En la parte inferior de la jarrita de Borriana vemos otra banda epigráfica algo más ancha, con letra cursiva de mayor altura. Los signos están pintados en negro,

40. BazzanA, André et alii: op. cit., p. 169 lám. XVII y fig. 48 p. $145, n^{\circ} 420$ p. 148. 


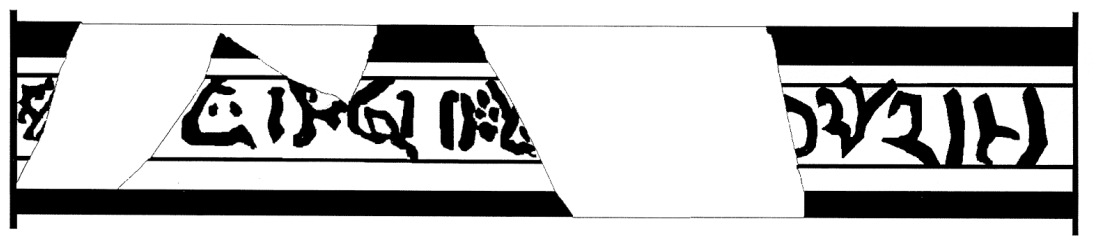

FIGURA 5. JARRITA DE LA CALLE MAYOR 26. RESTOS DE LA FRANJA EPIGRÁFICA SUPERIOR. Dibujo: Carmen Barceló

pero cuando estaba todavía cruda el artesano practicó una serie de incisiones verticales en el centro de cada carácter, no sabemos si para facilitar la lectura o para resaltar sus valores estéticos (Figura 6).

En origen, repetía seis veces al-mann 'el don', tres a cada lado de las asas; actualmente solo se conservan cuatro. Esta palabra no había sido recogida hasta fechas recientes en ningún repertorio de las expresiones que se leen sobre la cerámica andalusíi ${ }^{1}$, por lo que se podría pensar que se trata simplemente de una mala grafía del muy repetido término al-yumn 'la fortuna', con omisión de un signo. Pero dicha palabra está también en otras piezas, lo que apoyaría que aceptemos la propuesta de interpretar los trazos como al-mann. Se ve en el cuello de una jarra esgrafiada encontrada en la calle San Nicolás de Murcia ${ }^{42}$. En las excavaciones de 2009 realizadas en el solar de l'Almoina de Valencia se halló una jarrita esgrafiada en cuyo cuello figura repetido al-mann (SIAM I/I60) ${ }^{43}$.

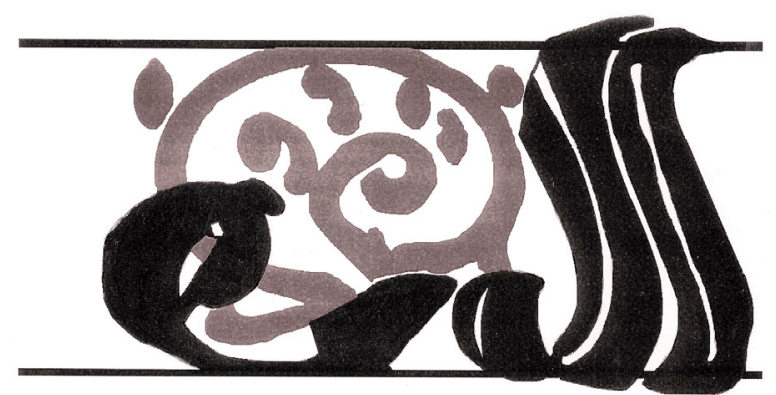

FIGURA 6. JARRITA DE LA CALLE MAYOR 26. MOTIVO EPIGRÁFICO AL-MANN EN LA FRANJA INFERIOR. DibujO: Carmen Barceló

Tenemos otro ejemplar aparecido en el Castillo de Albarracín que se considera de importación levantina; se trata de un fragmento cerámico de forma globular decorado con una banda epigráfica en letra cursiva esgrafiada sobre manganeso y

41. Barceló, Carmen: «Epigrafía...», p. 255, p. 242, fig. 2/4, p. 243, fig. 3C.

42. Navarro Palazón, Julio: Una casa islámica en Murcia. Estudio de su ajuar (siglo XIII). Murcia, Centro de Estudios Árabes y Arqueológicos «lbn Arabi», 1991, foto en p. 150, pieza nº 97-98.

43. BARCeló, Carmen: «Epigrafía...», p. 242, fig. 2/4. 
delimitada por líneas horizontales de esmalte azul turquesa como la de Borriana; en él se lee repetido al-mann ${ }^{44}$.

La expresión mann Allāh 'el don de Dios' está pintada en negro sobre blanco en el fondo de un bol encontrado en la calle Sagunto de Valencia ${ }^{45}$. Solo de manera anecdótica recordaremos que este término está en el título de la famosa crónica de Ibn Șāhị al-Ṣalā que narra los acontecimientos acaecidos en la península ibérica en época almohade (II59-II73): Kitāb al-mann bi-l-imāma.

Los caracteres de esta palabra, al igual que los de al-yumn, forman un ángulo recto que ocupa el costado derecho y la parte baja de un rectángulo, dejando vacío el centro y la esquina superior izquierda. Ese espacio se llenó tradicionalmente de decoración vegetal, realizada con detalle o esquematizada, incluyendo una flor de lis sobre la letra $<\mathrm{m}>$ y una espiral sobre $<\mathrm{n}>$. En este caso se ha optado por pintar una espiral y una serie de puntos.

Aunque con ciertas dudas y atendiendo a sus características morfológicas y decorativas, sugerimos que este producto pudo haber sido elaborado en algún centro del territorio valenciano; no se puede excluir su vinculación con alguno de los diversos alfares que trabajaban en Valencia capital.

\section{EPIGRAFÍA ÁRABE CON TÉCNICA ESTAMPILLADA}

En estos periodos tardíos del Islam andalusí, cierto tipo de contenedores de grandes dimensiones suelen presentar bandas epigráficas en la parte superior de su cuerpo, realizadas mediante la aplicación de un cuño o estampilla sobre el barro crudo. En algunos ejemplares se repite una sola palabra en varias fajas; en otros, la voz repetida en una banda se complementa con lo que dice otra situada en paralelo para formar una expresión más larga.

Algunas tinajas ofrecen decoración en toda su superficie, desde el pie hasta la boca como una del despoblado de Bolón (Museo de Elda ${ }^{46}$, una de Lorca y una de Mértola ${ }^{47}$, aunque la mayor parte la lleva en la mitad superior, sin que se pueda determinar si ello se debe a alguna relación con su contenido o con su ubicación. La letra puede ser cúfica o cursiva. El repertorio de términos que se documentan en estos recipientes es reducido: junto a los ya comentados baraka kāmila, albaraka, al-mulk, al-yumn, al-gibța, al-šukr, al-tawfīq, está 'äfiya 'bienestar', dándose

44. Ortega Ortega, Julián M.: Anatomía del esplendor. Fondos de la sala de Historia Medieval. Museo de Albarracín. Teruel, Fundación Santa María de Albarracín, 2007, p. 281, pieza 224, leído al-yumn 'la felicidad'.

45. Barceló, Carmen: «Epigrafía...», p. 255.

46. Aguado Villalba, José: Tinajas medievales españolas. Islámicas y mudéjares. Toledo, Diputación provincial, 1991, pp. 65, 80.

47. Lintz, Yannik; dÉlÉRy, Claire; TuIl Leonetti, Bulle (dir.) Maroc médiéval. Un empire de l'Afrique à l'Espagne. Paris, Musée du Louvre, 2014, pp. 344-345. 
a veces casos en los que las letras van al revés porque se ha usado para estampillar un trozo de tinaja con la leyenda en positivo ${ }^{48}$.

\subsection{FRAGMENTO DE TINAJA DE LA NUEVA CASA ABADÍA}

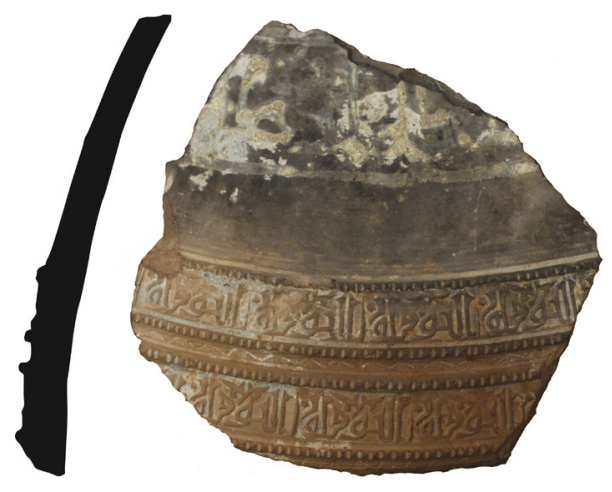

FIGURA 7. FRAGMENTO DE TINAJA ESTAMPILLADA de la nueva casa abadía. dibujo: autores. Foto: Museu de Borriana

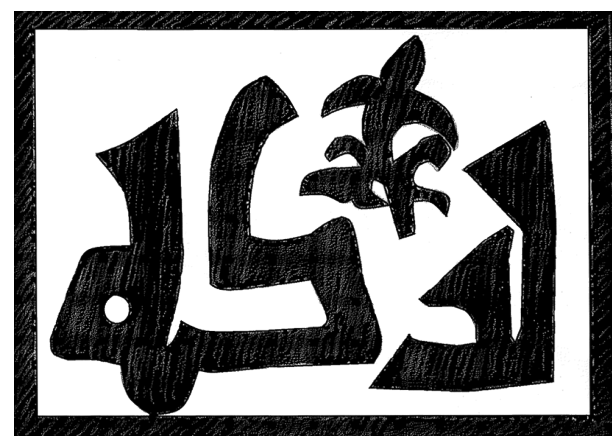

FIGURA 8. INSCRIPCIÓN VIDRIADA CON BARAKA en la tinaja de la nueva casa abadía. Dibujo: Carmen Barceló
El siguiente fragmento cerámico corresponde a una tinaja que proviene de la excavación de la nueva Casa Abadía, al igual que la pieza 2.1. antes comentada. Dimensiones: altura conservada de $\mathrm{I} 5 \mathrm{~cm}$; ancho conservado de $17,5 \mathrm{~cm}$ (Figura 7).

La tinaja estuvo decorada con estampillas. Responde al tipo que repite una sola palabra en varios registros. No toda su superficie estaba estampillada; al parecer en la parte alta del fragmento pudo llevar una inscripción más ancha, en escritura de estilo cúfico y realizada con otra técnica, tal vez vidriada con «cuerda seca» parcial, como se ve, entre otros, en un brocal de pozo cordobés de época almohade con la inscripción al-mulk ${ }^{49}$. El estado de degradación en que se encuentra actualmente esa parte y los escasos restos de letras conservados no permiten hoy una interpretación segura, si bien proponemos leer baraka 'gracia divina' (Figura 8).

Las dos bandas con estampillas están delimitadas por cenefas con incisiones en forma de gotas. Dentro hay una única palabra trazada en estilo cúfico, sin puntos ni vocales, pero con

48. Véase una estampilla invertida en: Aguado Villalba, José: Tinajas medievales españolas... p. 111; otra en Fernández Sotelo, Emilio: Ceuta medieval. Aportación al estudio de las cerámicas (s. X-XV). I. Cerámica de uso particular. Ceuta, Museo Municipal, 1988, p. 99, fig. 3, 3. Tres muestras más en CANO MONTORO, Encarnación: «Nueva aportación a la producción cerámica del barrio alfarero de época almohade de madinat Baguh (Priego de Córdoba): el hallazgo de tres tinajas estampilladas», ANTIQVITAS, 21 (2009), pp. 181-192.

49. LintZ, Yannik; Déléry, Claire; TuIL LeOnetTI, Bulle (dir.): op. cit. p. 397. 
adornos entre las letras para rellenar los espacios vacíos: una doble palmeta y una pequeña estrellita. El término que se repite en las dos cenefas de este trozo es altawfī 'el éxito'. Lo encontramos en multitud de tinajas y contenedores hallados en distintos puntos del territorio peninsular, como Córdoba ${ }^{50}$, Algeciras $^{51}$, Silves ${ }^{52}$, Mértola ${ }^{53}$.

La aplicación de la estampilla se ha realizado de una manera bastante correcta, respetando la integridad de la palabra. Esto no siempre sucede así pues, por ser la labor de impresión una tarea mecánica y rápida, muchas veces el alfarero borraba parte del final de lo impreso al sobreimponerle de nuevo el cuño ${ }^{54}$.

En el diseño del cuño de Borriana es de reseñar que el signo de la letra $y a \bar{a}$ t tiene igual altura que los dos trazos del artículo inicial, lo que constituye una anomalía en este tipo de escritura pero que observamos se produce de manera sistemática en esta palabra en todos los ejemplares de estampilla conocidos que la contienen, lo que implica un modelo inicial de prestigio con estas características (Figura 9).

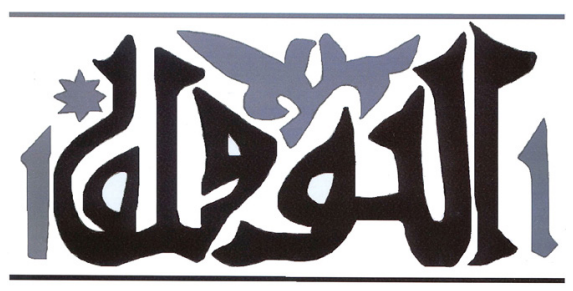

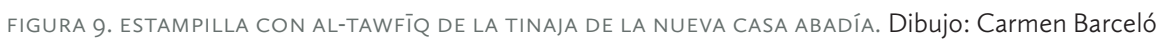

Suele acontecer en estos cuños que la letra $f a ̈$ ' tenga la cabeza sobreelevada y su trazo de unión con el siguiente signo adopte un quiebro. La finalidad de tal

50. SAntos, Samuel de los: «Estampillas de alfarerías moriscas cordobesas», Memorias de los Museos Arqueológicos Provinciales 1948-1949 (Extractos), 9-10, Madrid, Ministerio de Educación Nacional, 1950; al-tawfíq en p. 222, fig. 86 n 7937 y p. 223 fig. 87, V.9967. Hemos visto en una colección particular otro fragmento similar hallado en los antiguos vertederos del Polígono de Poniente.

51. TORRemochA, Antonio: «La cerámica musulmana estampillada de los siglos XIII y XIV hallada en Algeciras», Revista EPCCM, 17 (2015), pp. 349-402; cf. p. 372, lám. 12, Museo de Algeciras, $n^{\circ}$ Inv. 1831, leído al-iqbäl 'la prosperidad'. También en TORREMOCHA, Antonio: Algeciras musulmana y cristiana (sS. VIII-XIV). Estudios nº 9, Libros EPCCM, s. a., p. 164 lám. 55.

52. Gomes, Rosa: Silves (Xelb), uma cidade do Gharb Al-Andalus: a zona da Arrochela, espaços e quotidianos. Silves, Instituto de Gestâo do Património Arquitectónico e Arqueológico, 2011, incluye tres fragmentos de tinajas con dos estampillas distintas que contienen la voz al-tawfiq; cf. p. 392 fig. 2.55, E17 y E6 y p. 212, figura 1.92, pieza Q5/S. E15-1.

53. Cf. la tinaja vidriada en verde, datada en la segunda mitad del siglo XII o primeras décadas del XIII, encontrada en la alcáçova de Mértola (Museu de Mértola CR/ET/0067). Hay foto de detalle de las improntas en la contraportada de Arqueologia Medieval, 2, 1993. <http://islamicart.museumwnf.org/database_item.php?id=object;ISL;pt;Musol;12;pt> [20.11.2019].

54. CorreiA, Fernando Branco: «Um conjunto cerâmico árabe-medieval de Beja», A Cerâmica Medieval no Mediterrâneo Ocidental. Actas do IV Congresso Internacional. Lisboa 1987. Campo Arqueológico de Mértola, 1991, pp. 373-385; cf. lám p. 385 y 381, fig. 7: al-tawfíq. Lleva una palmeta en el mismo lugar que la de Borriana pero no se ve el final de cada estampilla porque está pisado por la siguiente. El autor indica en p. 377 n. 6 la semejanza de esta estampilla con una de Mértola. Lo mismo sucede en un fragmento hallado en Novelda, cf. AzUAR, Rafael; NAvarro, Concepción y Benito, Miguel: Excavaciones medievales en el castillo de La Mola (Novelda-Alicante). Novelda, Ayuntamiento, 1985, lám. 38 p. 89, nº 1637, leído en p. 122 al-ḥaqq 'la justicia'. 
diseño era dejar espacio al cuerpo inferior de $w a \bar{w}$, que en otros modelos quedaba oculto por el marco 55 .

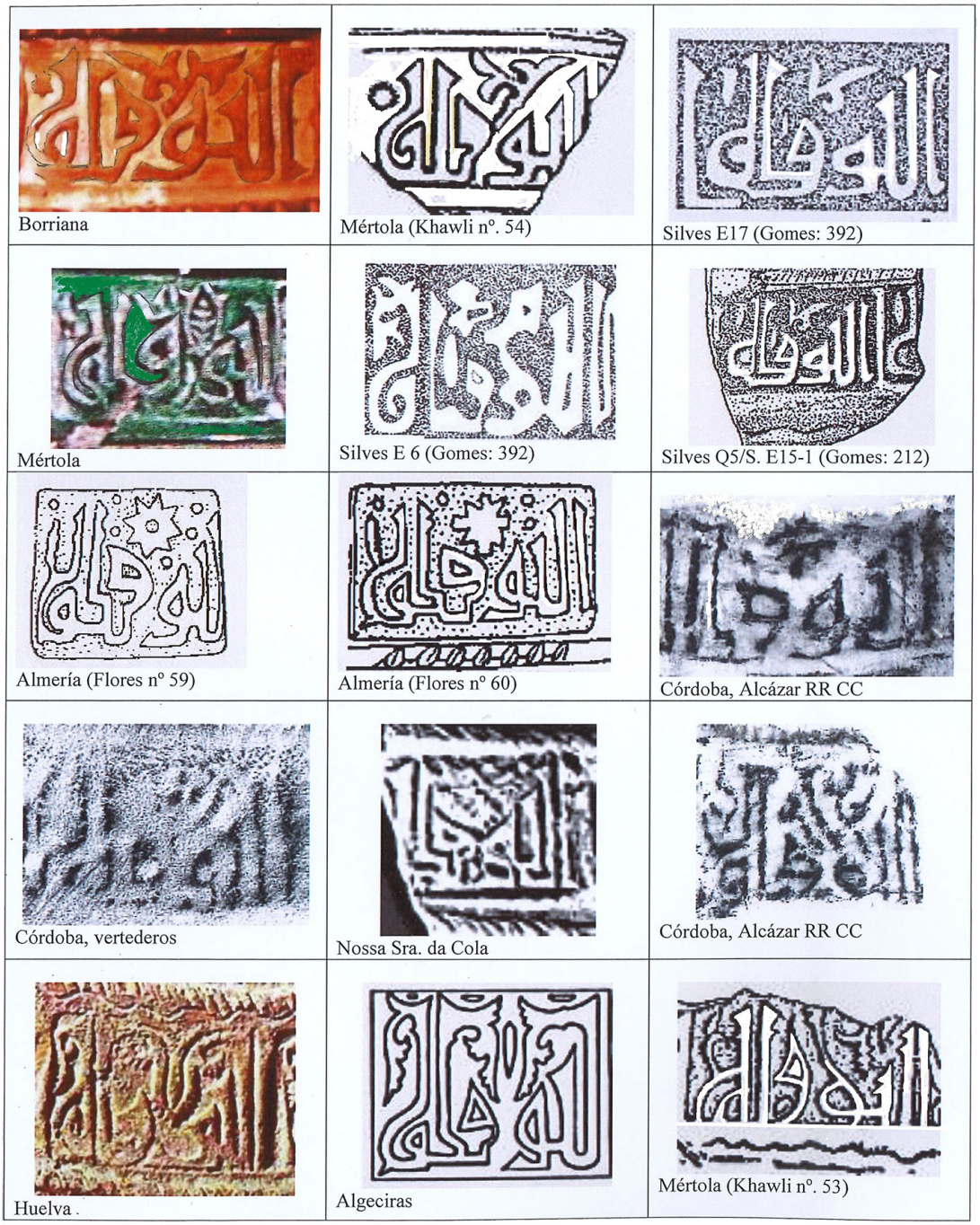

FIGURA 10. EL MOTIVO AL-TAWFīQ EN TINAJAS ESTAMPILLADAS. Elaboración: Ana Labarta

Una estampilla idéntica a la de la tinaja castellonense está en un pequeño fragmento de contenedor descubierto en la Alcáçova de Mértola (Portugal) dado

55. KHAWLI, Abdallah: «Lote de cerâmica epigrafada em estampilhagem de Mértola», Arqueologia Medieval, 1 (1992), pp. 7-25; cf. p. $24 \mathrm{n}^{\circ} 53$ (s. XII): al-tawfíq con la parte inferior de las letras tapada por la cenefa. 
como ilegible y datado entre los siglos XI y XII ${ }^{56}$. En algunos modelos, en lugar de la doble palmeta, en el espacio triangular que quedaba sobre las letras se diseñó una gran estrella de ocho puntas; así se observa en tinajas de Almería o Jijona ${ }^{57}$. Es habitual ver sellos con esta misma palabra en los que la letra $y \bar{a}$, para sortear la cabeza del signo anterior, presenta un quiebro angular hacia la izquierda antes de subir en vertical hasta alcanzar el borde superior de la caja de escritura, lo que le da un aspecto que puede inducir a confundirla con una letra käf. Los encontramos en Algeciras, Almería, Jijona, Nossa Senhora da Cola (Ourique, Beja, Portugal) ${ }^{58}$, Córdoba ${ }^{59}$ (Figura Io).

Suponiendo que nuestra tinaja no se destinara a almacenar grano, se usaría para contener agua, pues su interior carece de vedrío; en este caso, precisaría de un segundo elemento cerámico que haría de apoyo y recogedor del agua filtrada ${ }^{60}$. Una vez vertida el agua por la boca a su interior, iría rezumando al exterior a través de las paredes y la base y las impurezas se decantarían y depositarían en el fondo. Una de las piezas complementarias de la tinaja es el reposadero que, ubicado debajo de la misma, recoge el agua que esta exuda y, a través de un pitorro, la deposita en un recipiente ${ }^{6 \mathrm{I}}$.

Como se ha comentado, jarros con la misma forma y motivo decorativo que la de Borriana se han documentado en puntos de nuestra península muy alejados entre sí; nos enfrentamos a una gran dispersión y es imposible por ahora proponer para ninguna de ellas un centro productor.

\subsection{FRAGMENTO DE TINAJA DEL YACIMIENTO DE EL PALAU}

Este último fragmento corresponde también a una tinaja y proviene de la excavación de El Palau. Se localiza a $700 \mathrm{~m}$ de la medina y se ha relacionado con la antigua alquería de Beniham. En los años 2000 y 200 i se documentaron en ella

56. Idem p. $24 \mathrm{n}^{\circ} 54$.

57. Dominguez Bedmar, Manuel y EsPinar Moreno, Manuel: «Catalogación preliminar de estampillas almerienses», A Cerâmica Medieval no Mediterrâneo Ocidental. Actas do Iv Congresso Internacional. Lisboa 1987. Campo Arqueológico de Mértola, 1991, pp. 593-599, n 16: al-tawfíq. Aparecida en la Alcazaba de Almería nº inv. 44201. Es igual a la de la Torre Grossa, cf. AzuAR, Rafael: Castillo de la Torre Grossa (Jijona). Alicante, Diputación provincial, 1985, pp. 92-93, nº 160 y lám. 47 (fragmento $n^{\circ}$ TG-6898). Flores Escobosa, Isabel; Muñoz Martín, María del Mar; Lirola Delgado, Jorge: op. cit. p. 236 fig. $15 / 59$ y p. 236 fig. $15 / 60$.

58. VianA, Abel: «Nossa Senhora da Cola», O Arquivo de Beja, 17 (1961), apud CARdoso, João Luís: «Abel Viana (1896-1964): uma vida de arqueólogo», Estudos Arqueológicos de Oeiras, 21 (2014), pp. 475-510, cf. p. 503, fig. 54.

59. Dos fragmentos se exponen en: Alcázar de los Reyes cristianos, Patio Morisco, Galería Norte.

6o. Véanse las de Lorca y Mértola con sus respectivos apoyos en LinTZ, Yannik; DÉLÉRY, Claire; TUIL LeONETTI, Bulle (dir.): op. cit. pp. 344-345.

61. Navarro Palazón, Julio y Jiménez Castillo, Pedro: «Piletas de abluciones en el ajuar cerámico andalusí», Verdolay, 5 (1993), p. 175. Véanse reposaderos destinados a sustentar tinajas, jarras y jarritas, además de recoger el agua exudada por estas vasijas, en NAVARro PALAZÓN, Julio: «Formas arquitectónicas en el mobiliario cerámico andalusí», Cuadernos de la Alhambra, 23 (1987), pp. 21-64; NAVARRo PALAZÓn, Julio y JIMÉnEz CASTILLO, Pedro: «De nuevo sobre los aguamaniles cerámicos andalusíes: las tapaderas», Al-Ándalus-Magreb, 5 (1998), pp. 189-202; NAVARRO, Julio y JIMÉNEZ, Pedro: «Religiosidad y creencias en la Murcia musulmana: testimonios arqueológicos de una cultura oriental», Huellas: Catedral de Murcia, exposición, 2002, pp. 58-87. 
los restos de varias estancias y un molino. Con anterioridad se había excavado su cementerio. La fase más antigua de este yacimiento se ha fechado en el siglo IX y ha permanecido ocupado hasta hoy; con la conquista cristiana pasó a ser conocido como la alquería de El Palau ${ }^{62}$.

El fragmento de tinaja es bastante pequeño. Dimensiones: altura conservada de $6 \mathrm{~cm}$; ancho conservado de 7,5 cm. (Figura 11).

Está decorado con estampilla; conserva parte de una cinta con restos incompletos de dos improntas consecutivas, realizadas con un único sello que llevaba tallado el adjetivo kāmila 'completa'. Es posible que hubiera en la misma pieza, que pudo ser una tinaja o también un brocal de pozo, una banda paralela en la que se repetiría el término baraka 'gracia divina' y juntas formarían la conocida expresión árabe baraka kāmila, presente en todo tipo de objetos desde épocas mucho más antiguas.
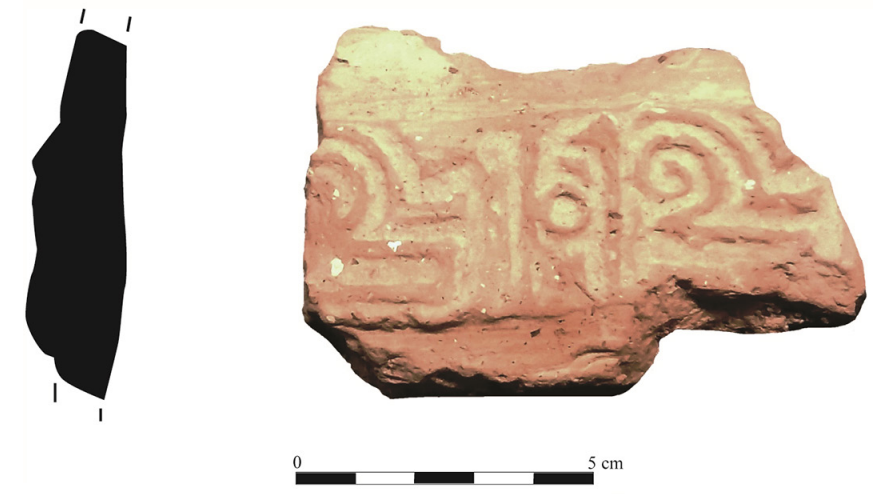

FIgURA 11. FRAGMENTO DE TINAJA DEL YACIMIENTO DE EL PALAU. Foto: Museu de Borriana

Los rasgos epigráficos presentes en esta impronta son muy característicos, pues el ápice superior de la letra kāf adopta forma de espiral hacia la izquierda, en lugar de ser recto o quebrado formando ángulos. Es a partir de finales del siglo xI y sobre todo en el xil cuando vemos el ápice de kâf curvarse hacia la izquierda en zócalos pintados de viviendas malagueñas del siglo Xiı ${ }^{63}$.

Para rellenar el ángulo superior derecho de la estampilla, se dibujó un segundo perfilado de esta letra y sobre él otro en forma de v o palmeta. El alif remata en un apéndice triangular hacia la izquierda, como también lām; mīm está en una posición muy elevada, en el centro del ancho de la banda epigráfica. La palabra está incompleta, pues la segunda impresión ha tapado la última letra del adjetivo (Figura I2).

62. Melchor Monserrat, José Manuel y Benedito Nuez, Josep: El Palau (Burriana). Procesos de cambio cultural desde la Prehistoria hasta el siglo xx. Burriana, Ayuntamiento, 2016.

63. OCAÑA JimÉNEZ, Manuel: op. cit., en especial láms. 14 y 15/1. 


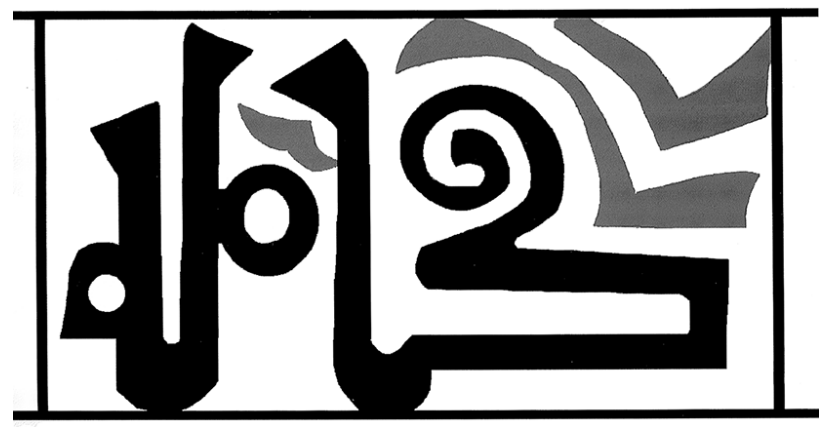

FIGURA 12. RECONSTRUCCIÓN DE LA ESTAMPILLA CON KĀMILA DE LA TINAJA DE EL PALAU. Dibujo: Carmen Barceló

Los objetos con estampillas en los que se usa este calificativo son abundantes; recordaremos los de Córdoba ${ }^{64}$, un trozo de tinaja encontrado en Buñol (sıAM), el borde de un brocal de pozo aparecido en excavaciones de 2015 en Cuatrovitas (Sevilla) $)^{65}$, un fragmento descubierto en Quesada (Jaén) ${ }^{66}$ o un trozo amorfo de Almería ${ }^{67}$. La pieza descubierta durante excavaciones en el castillo de Buñol ${ }^{68}$ muestra esta misma palabra y también con una letra mim en el centro de la banda epigráfica, aunque el resto de los trazos no sea coincidente con los signos del sello que nos ocupa.

Como sucede con el ejemplar anterior, tenemos dudas en cuanto a su posible centro de producción. Los paralelos a nivel formal y decorativo son también amplios, aspecto que dificulta vincularlo a un alfar concreto.

\section{CONCLUSIONES}

Se han analizado en este artículo dos jarritas islámicas esgrafiadas y pintadas con óxido de manganeso y dos fragmentos de tinaja con decoración estampillada descubiertos en trabajos arqueológicos realizados en Borriana.

En ausencia de análisis de las pastas, poco puede afirmarse sobre cuál pudo ser el centro alfarero del que procede cada una de estas piezas, lo cual nos lleva a ser muy cautelosos en la propuesta de un origen. Por otro lado, sus formas están presentes en muchas localidades de al-Andalus y poco aportan para determinar los centros de producción.

64. SANTOS, Samuel de los: op. cit., en p. 221 n 9926 : kämila.

65. Agradecemos imagen y noticia a la arqueóloga Anja Heidenreich.

66. Riera Frau, M. ${ }^{a}$ Magdalena; Rosselló Bordoy, Guillermo y Soberats Sagreras, Natalia: «Tinajas con decoración estampada de época almohade de Quesada (Jaén)», Arqueología y territorio medieval, 4 (1997), p. 167.

67. Flores Escobosa, Isabel; Muñoz Martín, María del Mar; Lirola Delgado, Jorge: op. cit. p. 236 fig. 15/62.

68. Agradecemos imagen y noticia a la arqueóloga Pau Armengol. 
Como es sabido, el esgrafiado comienza a aparecer en contextos arqueológicos fechados en la época de los imperios norteafricanos, a partir del siglo xıl, y continúa durante la centuria siguiente, hasta la conquista cristiana de cada lugar, I233 en el caso de Borriana. El área murciana y levantina concentra el mayor número de hallazgos con esta característica, que también se han documentado en Baleares, Andalucía, Algarve y algunos centros norteafricanos.

La jarrita descubierta en las excavaciones de la nueva Casa Abadía es una pieza realmente excepcional, que ha llegado hasta nosotros en un estado de conservación aceptable. Es un ejemplar que destaca por su calidad artística, pues la decoración epigráfica con la técnica del esgrafiado se encuentra en un número reducido de objetos cerámicos en este territorio de la costa levantina. Este tipo de jarrita con pie anular, cuerpo globular, cuello ligeramente abocinado, dos asas de sección ovalada y una decoración muy refinada alcanzó un gran desarrollo en la región de Murcia. Con todas las cautelas y atendiendo a sus paralelismos tipológicos y decorativos (roleos, retículas, franja epigráfica exterior y grafía en el interior del cuello) se podría proponer que se trate de una producción elaborada en el área murciana.

La jarrita que salió a la luz en las excavaciones de la calle Mayor 26 tiene diferencias apreciables con los ejemplares murcianos en lo que se refiere al esquema compositivo, con motivos semejantes, en algunos casos, pero no idénticos. Su ornamentación en cambio es muy similar al cuello de jarrita encontrado en la calle Avellanas de Valencia (sıAm 823), que presenta idénticas cartelas que repiten el término al-salāma, pintadas entre roleos esgrafiados y líneas de vidriado. El estudio de su forma y la identificación de sus características decorativas permiten destacar similitudes con las del área valenciana fechables en el primer cuarto del siglo xıı y proponer, también con las cautelas oportunas, su posible procedencia de un centro productor que se hallaría en el área levantina o incluso en la ciudad de Valencia.

No se puede establecer con precisión el tamaño ni deducir el resto de la forma de las tinajas burrianenses, pues únicamente se conservan fragmentos informes. Su decoración estampillada se debe relacionar con la época almohade pero la abundancia y dispersión de este tipo de productos hace imposible proponer su atribución a un centro alfarero concreto.

Del ejemplar hallado en la Nueva Casa Abadía únicamente se puede afirmar que se trataba de un gran contenedor de cuerpo globular y forma cerrada. La comparación de la estampilla usada en este fragmento con las de otras tinajas del territorio peninsular ha permitido localizar paralelos con su mismo motivo epigráfico en Córdoba, Jaén, Algeciras, Silves, Jijona, Beja o Mértola, mientras que la palabra estampada en el fragmento cerámico de El Palau se ha encontrado en contenedores de Almería, Sevilla y Buñol.

En conclusión, y a falta de estudios más técnicos de composición de pastas, parece que estamos ante cuatro productos alfareros de importación, datables 
en periodo almohade. Dos podrían ser contenedores para agua o conservación de provisiones que debían estar presentes en cualquier vivienda, fuera de la categoría que fuera. Por el contrario, los dos bellos ejemplares esgrafiados y pintados aparecidos, además, en el corazón de la medina medieval son piezas de mejor elaboración y hacen factible suponer que su presencia responda al hábitat de individuos con cierta categoría social y tal vez responsabilidades civiles y/o militares. 


\section{BIBLIOGRAFÍA}

Abellán, Juan; Blanco, Francisco José; Espinar, Manuel; Carreras, A. María: «Cerámica hispano-musulmana de la provincia de Cádiz. Primeras piezas halladas en el yacimiento de Los Caños de Meca», Il Coloquio Internacional de Cerámica Medieval en el Mediterráneo Occidental, Madrid, Ministerio de Cultura, I986, pp. I4I-I47.

Aguado Villalba, José: Tinajas medievales españolas. Islámicas y mudéjares. Toledo, Diputación provincial, I99I.

Álvaro Zamora, María Isabel: «La cerámica andalusí», Artigrama, 22 (2007), pp. 337-369.

Amigues, François; Mesquida, Mercedes y Soler, M. ${ }^{a}$ Paz: «La cerámica esgrafiada en los talleres mudéjares de Paterna (Valencia)», Actas Congreso A Cerámica Medieval no Mediterrâneo Ocidental, Mértola, I991, pp. 305-3I4.

AtaAllah, Mohamed: «Céramiques musulmanes à paroi fine incisée ou peinte de Lixus», Bulletin d'Archéologie Marocaine, 7 (1967), pp. 627-639.

Azuar Ruiz, Rafael: Castillo de la Torre Grossa (Jijona). Alicante, Diputación provincial, I985.

Azuar Ruiz, Rafael: «Alfares y Testares del Sharq Al-Andalus (siglos xil-XIII). Producción, tipología y distribución», en Padilla, José l. y Vila, Josep M. (coords.), Ceràmica Medieval i Postmedieval. Circuits productius i seqüències culturals, Barcelona, Universitat de Barcelona, I998, pp. 57-7I.

Azuar, Rafael; Navarro, Concepción y Benito, Miguel: Excavaciones medievales en el castillo de La Mola (Novelda-Alicante). Novelda, Ayuntamiento, 1985.

Azuar, Rafael; Borrego, Margarita; Martí, Javier; Navarro, Concepción; Pascual, Josefa; Saranova, Rosa; Burguera, Vicent; Gisbert, Josep Antoni: «Cerámica tardoandalusí del País Valenciano (Primera mitad del siglo xiıl)», Actes $d u 5^{\text {ème }}$ Colloque sur la Céramique Médiévale (Rabat II-I7 Novembre I99I), Rabat, Institut National des Sciences de l'Archéologie et du Patrimoine, I995, pp. I40-I6I.

BARCELÓ, Carmen: «La epigrafía ornamental», La cerámica islámica en la ciudad de Valencia II. Estudios, Valencia, Ayuntamiento, I990, pp. I37-I42.

BARCELó, Carmen: «El cúfico andalusí de 'provincias' durante el Califato (300-403/912IOI3)», Cuadernos de Madinat al-Zahrâ',, 5 (2004) [Actas de las Iv Jornadas de Madinat al-Zahrâ',: Nuevas investigaciones sobre el Califato de Córdoba], pp. I73-I97.

BARCELó, Carmen: «Epigrafía árabe en cerámica», en LeRMA AlEgria, Josep Vicent (com.): L’Argila de la mitja lluna. La ceràmica islàmica a la ciutat de València. 35 anys d'arqueologia urbana. València, Ajuntament, 2018, pp. 233-266.

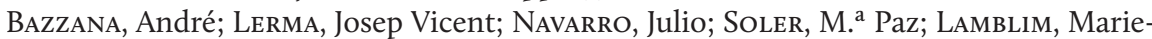
Pascale; Montmessin, Yves: La cerámica islámica en la ciudad de Valencia [I]. Catálogo. Valencia, Ayuntamiento, I983.

Bazzana, André y Montmessin, Yves: «Quelques aspects de la céramique médiévale du Maroc du Nord: problèmes typologiques et chronologiques», en Actes du $5^{\text {ème }}$ Colloque sur la Céramique Médiévale (Rabat II-I7 Novembre I99I), Rabat, Institut National des Sciences de l'Archéologie et du Patrimoine, I995, pp. 24I-259.

CANo Montoro, Encarnación: «Nueva aportación a la producción cerámica del barrio alfarero de época almohade de madinat Baguh (Priego de Córdoba): el hallazgo de tres tinajas estampilladas», ANTIQVITAS, 2I (2009), pp. I8I-I92.

CARDOSO, João Luís: «Abel Viana (I896-I964): uma vida de arqueólogo», Estudos Arqueológicos de Oeiras, 2I (2014), pp. 475-5IO. 
CAvilla SÁnchez-Molero, Francisco: «Las cerámicas esgrafiadas de Cádiz y la difusión de las producciones esgrafiadas en el suroeste peninsular y El Magreb», Estudios sobre patrimonio, cultura y ciencias medievales, 5-6 (2004), pp. 37-54.

Claramonte, Mónica y Benedito, Josep: «La cerámica hispanomusulmana y mudéjar», La arqueología de la Buriyyana islámica a la Borriana cristiana. Burriana, Ayuntamiento, 2OII, pp. I03-I24.

COLl CONESA, Jaume: «Ceràmica i canvi cultural a la València medieval. L'impacte de la Conquesta», Afers, 7 (I989), pp. I25-I67.

COLl ConesA, Jaume: «La ceràmica valenciana del segles xilı al xix. Tècniques i processos de la producció. Visió diacrònica de conjunt», en PADilla, Josep I. y Vila, Josep M. (coords.): Ceràmica Medieval i Postmedieval. Circuits productius i seqüencies culturals. Barcelona, Universitat de Barcelona, I998, pp. 165-176.

COLl CONESA, Jaume: La cerámica valenciana (apuntes para una síntesis). Valencia, Asociación Valenciana de Cerámica, 2009.

Coll, Jaume y GARCía, Alberto: «Tipología, cronología y producción de los hornos cerámicos en al-Andalus», Albisola, xuII (2010), pp. 7-24.

Coll, Jaume; HuÉlamo, José María y Solias, José María: «Avance de un estudio sobre los restos materiales del castillo islámico de Cuenca», Actas I Congreso de Arqueología Medieval Española III, Huesca, I989, pp. 77-97.

COLL, Jaume y MarTínez, Virgilio: «La ocupación medieval», Lixus-2 ladera sur. Excavaciones arqueológicas marroco-españolas en la colonia fenicia. Campañas 2000-2003. Saguntum extra 6 (2005), pp. 37-70.

COLl, Jaume; PASCUAL, Josefa y MARTí, Javier: Cerámica y cambio cultural. El tránsito de la Valencia islámica a la cristiana. Madrid, Dirección General de Bellas Artes y Archivos, I989.

CORREIA, Fernando Branco: «Um conjunto cerâmico árabe-medieval de Beja», A Cerâmica Medieval no Mediterrâneo Ocidental. Actas do IV Congresso Internacional. Lisboa 1987. Campo Arqueológico de Mértola, I991, pp. 373-385.

Crónica del moro Rasis. Edición D. Catalán y S. de Andrés, Madrid, I975.

Crespo Pascual, Almudena: «Cerámica esgrafiada: estado de la cuestión», Anales de Arqueología Cordobesa, I2 (2001), pp. 353-370.

Delpy, Alexandre: «Note sur quelques vestiges de céramique recueillis à Salé», Hespéris. Archives Berbères et bulletin de l'institut des hautes études marocaines, 42 (I955), pp. I29-I52.

De MARía, Ramón: El repartiment de Burriana y Villarreal. Vila-real, Caja Rural CatólicoAgraria S. Coop. de Crédito, Ltda., I933.

Dominguez, Manuel y Espinar, Manuel: «Catalogación preliminar de estampillas almerienses», A Cerâmica Medieval no Mediterrâneo Ocidental. Actas do IV Congresso Internacional. Lisboa 1987. Campo Arqueológico de Mértola, I99I, pp. 593-599.

Edrîsî. Description de l'Afrique et de l'Espagne. Edición y traducción R. Dozy et M. J. de Goeje, Leiden, Brill, I866, reimpresión anastática I968.

FERnÁNDEZ, Alejandro; MARTín, Miguel Á. y MoREDA, Javier: «Excavaciones arqueológicas en el monasterio de San Benito el Real de Valladolid. Un interesante fragmento de cerámica esgrafiada y cuerda seca parcial», Boletín de Arqueología Medieval, 3 (I989), pp. 233-24I.

Fernández Sotelo, Emilio: Ceuta medieval. Aportación al estudio de las cerámicas (s. X-XV). I. Cerámica de uso particular. Ceuta, Museo Municipal, I988.

Ferrer, Agustín y Pelufo, M. a Ángeles: «Estudio de las cerámicas esgrafiadas de Al-Gezira Suqar», Al-Gezira. Revista d'Estudis Històrics-Ribera Alta, 4/5 (I988), pp. 47-73.

Flores, Isabel; MuÑoz, María del Mar; LiROLA, Jorge: «Las producciones de un alfar islámico en Almería», Arqueología y Territorio Medieval, 6 (I999), pp. 207-239. 
GARCíA, Vicent: Llibre de privilegis de Borriana (I233-I350). Burriana, Collecció Papers I4, I989.

Gomes, Rosa Varela: Silves (Xelb), uma cidade do Gharb Al-Andalus: a zona da Arrochela, espaços e quotidianos. Silves, Instituto de Gestâo do Património Arquitectónico e Arqueológico, 20II.

Gomes, Rosa Varela: «Cerâmicas muçulmanas do Castelo de Silves», XELB: revista de arqueologia, arte, etnologia e história, I (I988), pp. 9-294.

Gomes, Rosa Varela y Gomes, Mário Varela: Palácio Almoada da Alcáçova de Silves. Lisboa, Museo Nacional de Arqueologia, 20oI.

Gómez Martínez, Susana: La cerámica islámica de Mértola producción y comercio, (Tesis Doctoral inédita), Universidad Complutense de Madrid, 2004.

Gómez Martínez, Susana: «El arrabal portuario de Mértola (Portugal): el registro cerámico andalusí», revista Onoba, 4 (2016), pp. I8I-I96.

Guichard, Pierre: «Los orígenes islámicos», Burriana en su historia I. Burriana, Ajuntament, I987, pp. 7I-87.

Guichard, Pierre: Al-Andalus frente a la conquista cristiana: los musulmanes de Valencia, siglos XI-XIII. Valencia, Universitat de València, 200I.

Guillermo Martínez, Martín: Cartagena medieval. Cartagena, Cuadernos Monográficos del Museo del Teatro Romano, 2014.

HeIDENREICH, Anja: Islamische Importkeramik des hohen Mittelalters auf der Iberischen Halbinsel. Madrid, Deutsches Archäeologisches Institut, 2007.

Hita, José Manuel y Villada, Fernando: «Producción y comercialización de la cerámica esgrafiada y pintada en el ámbito de El Estrecho de Gibraltar. El caso de Ceuta», Almoraima, 42 (20II), pp. 215-238.

Huici Miranda, Ambrosio: Historia musulmana de Valencia y su región. Valencia, Ayuntamiento, I970.

AL-IDRīisi. Los caminos de al-Andalus en el siglo XII. Edición y traducción Jassim Abid Mizal. Madrid, CSIC, I989.

Jenkins-Madina, Marilyn: Medieval Maghribî Ceramics. A Reappraisal of the Pottery Production of the Western Regions of the Muslim World. New York, New York University, I979.

KHAwLl, Abdallah: «Lote de cerâmica epigrafada em estampilhagem de Mértola», Arqueologia Medieval, I (I992), pp. 7-25.

LabARTA, Ana; BARCEló, Carmen; Veglison, Josefina: València àrab en prosa i vers. València, Publicacions de la Universitat de València, 2oII.

Lerma Alegria, Josep Vicent: «Relaciones mediterráneas de la Valencia islámica: las cerámicas importadas», Les Illes Orientals d'Al-Andalus i les seues relacions amb Sharq AlAndalus, Magrib i Europa cristiana, actas de V Jornades d'Estudis Històrics Locals, Palma, I987, pp. 339-358.

LERMA AlEgRIA, Josep Vicent (com.): L'Argila de la mitja lluna. La ceràmica islàmica a la ciutat de València. 35 anys d'arqueologia urbana. València, Ajuntament, 2018.

LÉvi ProvençAL, E.: «La description de l'Espagne d'Ahmad al-Râzî. Essai de reconstitution de l'original arabe et traduction française», Al-Andalus, xvili (I953), pp. 5I-Io8.

Lintz, Yannik; DélÉRY, Claire; TUIL LeOnetti, Bulle (dir.) Maroc médiéval. Un empire de l'Afrique à l'Espagne. Paris, Musée du Louvre, 2014.

Llibre del repartiment del Regne de Valencia. Edición, estudio preliminar e índices M. ${ }^{a} \mathrm{D}$. Cabanes Pecourt y R. Ferrer Navarro, 2 vols. Zaragoza, Anúbar, I979.

MARÇAIS, Georges: Les poteries et faïences de Bougie (collection Debruge). Contribution a l'étude de la céramique musulmane, Constantine, Braham, I9I6. 
Melchor Monserrat, José Manuel: «La arqueología como fuente de estudio para la Burriana medieval», La arqueología de la Buriyyana islámica a la Borriana cristiana. Burriana, Ayuntamiento, 20II, pp. II-48.

Melchor, José Manuel y Benedito, Josep: El Palau (Burriana). Procesos de cambio cultural desde la Prehistoria hasta el siglo xx. Burriana, Ayuntamiento, 2016.

Navarro Palazón, Julio: La cerámica esgrafiada andalusí de Murcia. Madrid, Casa de Velázquez, I986.

Navarro Palazón, Julio: La cerámica islámica en Murcia. Vol. I. Catálogo. Murcia, Ayuntamiento, I986.

Navarro Palazón, Julio: «Hacia una sistematización de la cerámica esgrafiada». II Coloquio Internacional de Cerámica Medieval en el Mediterráneo Occidental, Madrid, Ministerio de Cultura, I986, pp. I65-178.

NAVArro PAlazón, Julio: «Formas arquitectónicas en el mobiliario cerámico andalusí», Cuadernos de la Alhambra, 23 (I987), pp. 2I-64.

Navarro PAlazón, Julio: «La cerámica con decoración esgrafiada», La cerámica islámica en la ciudad de Valencia II. Estudios, Valencia, Ayuntamiento, I990, pp. II5-I35.

Navarro Palazón, Julio: Una casa islámica en Murcia. Estudio de su ajuar (siglo XiII). Murcia, Centro de Estudios Árabes y Arqueológicos «Ibn Arabi», I99I.

Navarro, Julio y Jiménez, Pedro: «Piletas de abluciones en el ajuar cerámico andalusí», Verdolay, 5 (I993), pp. I7I-I77.

Navarro, Julio y JimÉnez, Pedro: «Maquetas arquitectónicas en cerámica y su relación con la arquitectura andalusí», en Navarro, Julio (ed.), Casas y palacios de Al-Ándalus (Siglos XII y XIII). Barcelona - Granada, Lunwerg - El Legado andalusí, I995, pp. 287-302.

Navarro, Julio y Jiménez, Pedro: «La cerámica andalusí de Siyâsa: estudio preliminar», Cerâmica Medieval e Pós-Medieval, métodos e resultados para o seu estudo, Actas das $3^{\text {a }}$ Jornadas Tondela (Portugal), I997, pp. I03-I23.

NAVARro, Julio y JıMÉNEZ, Pedro: «De nuevo sobre los aguamaniles cerámicos andalusíes: las tapaderas», Al-Ándalus-Magreb, 5 (1998), pp. I89-202.

Navarro, Julio y JimÉnez, Pedro: «Religiosidad y creencias en la Murcia musulmana: testimonios arqueológicos de una cultura oriental», Huellas: Catedral de Murcia, exposición, 2002, pp. 58-87.

Navarro, Julio y Jiménez, Pedro: «La cerámica andalusí de Murcia a la llegada de Alfonso x», Alfonso x y su época. Catálogo de la exposición celebrada en Murcia. Murcia, 2009, pp. 695-704.

OCAÑA JIMÉNEZ, Manuel: «Zócalos hispanomusulmanes del siglo xıı», Al-Andalus, Io/I (I945), pp. I64-I69.

Ortega Ortega, Julián M.: Anatomía del esplendor. Fondos de la sala de Historia Medieval. Museo de Albarracín. Teruel, Fundación Santa María de Albarracín, 2007.

Ramón Fernández, Francisca: El ingreso en la comunidad de pescadores de El Palmar y la transmisión hereditaria del «redolí». Valencia, Publicacions de la Universitat de València, 200I.

Riera, M. ${ }^{a}$ Magdalena; Rosselló, Guillermo y Soberats, Natalia: «Tinajas con decoración estampada de época almohade de Quesada (Jaén)», Arqueología y territorio medieval, 4 (I997), pp. I63-180.

SAntos, Samuel de los: «Estampillas de alfarerías moriscas cordobesas», Memorias de los Museos Arqueológicos Provinciales 1948-I949 (Extractos), 9-Io, Madrid, Ministerio de Educación Nacional, I950, pp. 220-232. 
Torremocha SiLva, Antonio: «La cerámica musulmana estampillada de los siglos xill y XIv hallada en Algeciras», Revista EPCCM, I7 (2015), pp. 349-402.

Torremocha Silva, Antonio: Algeciras musulmana y cristiana (ss. VIII-XIV). Estudios Núm. 9, Libros ЕРССм, s. a.

VianA, Abel: «Nossa Senhora da Cola», O Arquivo de Beja, I7 (I96I). 
Calidad de Revistas

científicas Españolas

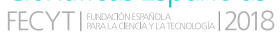

SERIE III HISTORIA MEDIEVAL

REVISTA DE LA FACULTAD DE GEOGRAFİA E HISTORIA
AÑO 2021

ISSN: 0214-9745

E-ISSN 2340-1362

\section{4 \\ issacio. \\ TIEMPO \\ Y FORMA}

\section{Volumen I}

\section{Artículos · Articles}

15 Patricia A. Argüelles Álvarez

Peligros, inseguridades y problemas del viajero visigodo

37 Carmen Barceló, Ana labarta, Josep Benedito \& José M. MELCHOR

Cuatro cerámicas con epigrafía árabe del Museu de Borriana

65 CARlos BARQuero Goñ

Organización de la Orden de San Juan en Castilla durante los siglos XII y XIII

113 Francisco de Paula Cañas Gálvez

Una infanta de Navarra en la corte de Castilla: escenarios políticos en torno a la configuración y evolución del Hostal y la casa de Blanca de Trastámara, Princesa de Asturias (1424-†1464)

\section{David Caramazana Malia}

Las promociones artísticas de Alonso de Ejea, arzobispo y administrador perpetuo de la Archidiócesis de Sevilla y patriarca de Constantinopla (1403-1417)

\section{Pedro Castillo Maldonado}

Privilegios episcopales: la inviolabilidad de los obispos visigóticos y el delito de lesa majestad

\section{MÁxIMO DIAGO HERNANDO}

Alonso de Fonseca, Obispo de Ávila, Cuenca y Osma, y el ascenso de un linaje de exiliados portugueses en la Castilla de los siglos XV y XVI

\section{Antonio PIO dI Cosmo}

Santa Brigida ed il Monte Gargano: un paesaggio dell'anima. La descrizione dell'ambiente come stratagemma d'ammaestramento morale

\section{FERRAN ESQUILACHE}

La 'fila' de agua valenciana y otras medidas de aforo. La verdadera naturaleza de un sistema de medición de caudales de origen andalusí

\section{Alejandro Esteban Álvarez}

Habices del Reino de Granada averiguados en 1528 y 1531: la țā'a nazarí de Órgiva (Alpujarra)

\section{JaVier Gómez Gómez \& IÑAKı MARTín VISO}

Rationes y decimas: evidencias sobre la gestión de las sernas en el siglo XI en el noroeste de la Península Ibérica
383 SANTIAGO GONZÁLEZ SÁNCHEZ

Aportaciones de Paredes de Nava a las campañas militares de Infante Don Fernando, señor de la villa y regente de Castilla, contra el Reino Nazarí de Granada en 1407 y en 1410

429 ANTONI LLIBRER ESCRIG

Una máquina para la industria medieval. Los batanes del sur valenciano: integración y negocio. Nuevas aportaciones (1490-1502)

455 José Miguel López Villalba Comunicación escrita y oral de la ordenanza municipa (siglos XV-XVI)

501 Emilio Martín Gutiérrez

El aprovechamiento de los recursos naturales: la grana en Andalucía occidental durante el siglo XV

\section{Volumen II}

537 VERA-CRuz Miranda MENACHO

$(1421-1461)$

Las finanzas de un heredero: Carlos de Aragón y Navarra

569 Raúl Morales Muñoz

Hacia una revalorización del conciliarismo hispano bajomedieval: el Defensorium Trium Conclusionum de Alfonso de Madrigal

605 David Nogales Rincón

Enrique III de Castilla (1390-1406) y la indagación de rentas: un proyecto regio para la búsqueda de mineros y tesoros a inicios de cuatrocientos

6.7.7 Gonzalo Oliva Manso

Seisenes y novenes. Tiempos de calma para la moneda castellano-leonesa (1282-1312)

685 Alberto Peña Fernández y Manuel García Alonso Una inscripción medieval inédita en la iglesia de San Miguel de Aguayo (Cantabria)

713 RODRIGO POUSA DIÉGUEZ

Configuración institucional de una villa costera: Muros en el tránsito de la Edad Media a la Edad Moderna

\subsection{JuAn A. Prieto Sayagués}

Las profesiones femeninas de la nobleza y de las oligarquías urbanas en la Castilla bajomedieval. Causas, dinámicas, privilegios y donaciones 


\section{4}

\section{ESPACIO,}

\section{TIEMPO}

Y FORMA

UกED

SERIE III HISTORIA MEDIEVAL

REVISTA DE LA FACULTAD DE GEOGRAFÍA E HISTORIA

815 María del Pilar Rábade Obradó

El miedo a la Inquisición en la Castilla de los Reyes Católicos

84.5 Carlos Manuel Reglero de la Fuente

EL abad contra el rey (y los regidores): conflicto de jurisdicciones y ejercicio del poder en Sahagún (1398-1417)

881 Manuel Alejandro Rodríguez de la Peña

Eusebius and Alcuin on Constantine and Charlemagne as Wise Rulers: Sapiential Rulership in Late Antiquity and the Early Middle Ages

9)15 Antonio SÁnCHEZ GonzÁlez

El Archivo de los Mariscales de Castilla y Marqueses de Malagón

\section{Estudios y comentarios}

9. 51 Serafín Olcoz Yanguas

Apostilla al estudio Influencia de las redes nobiliarias en la expansión cristiana del siglo XII: el caso de Soria (ETF, 33, 2020)

\section{Libros · Books}

969 CAstrillo CASAdo, Janire, Las mujeres vascas durante la Baja Edad Media (MARía Jesús Fuente)

973 Crónica del rey Juan II de Castilla. Minoría y primeros años de reinado (1406-1420) GARCIA, Michel (edición y estudio) (VÍctor MUÑ̃z GómEZ)

981 DA Silva, Marcelo Cândido, História Medieval (DIEgo CARLo AMÉNDOLLA SPÍNOLA)

9.87 Galende Díaz, Juan Carlos y Ávila SeoAne, Nicolás, El rodado regio hispánico. Fernando III de León y Castilla (12301252) (MAURICIO HERRERO JIMÉNEZ)

989 García IzQuierdo, Iván, Frontera, fuero y concejos. EI valle del Riaza en la Edad Media (siglos VIII-XII) (CARLOS BARQUERO GOÑI)

993 García IzQuierdo, Iván y Peterson, David (coords.), Camino y Señorío. Obra selecta de Luis Martínez García (ENRIQUe CANTERA MONTENEgRO)

995 GonzÁlez PAz, Carlos Andrés, O Bispado de Mondoñedo na Idade Media. Territorio, comunidade e poder (ENRIQUE CANTERA Montenegro) 


\section{4}

\section{ESPACIO,}

\section{TIEMPO}

Y FORMA

UกED

SERIE III HISTORIA MEDIEVAL

REVISTA DE LA FACULTAD DE GEOGRAFİA E HISTORIA

\section{Libros · Books}

9) López MARtínez, Amalia, Minutarios notariales de Estevo Pérez (Ourense, siglo XIV) (José MIgUel LóPEz VILLALBA)

999 Miranda García, Fermín y López de Guereño SAnz, María Teresa (eds.), La muerte de los príncipes en la Edad Media. Balance y perspectivas historiográficas (ANA ECHEVARRÍA ARSUAGA)

1003 Motis Dolader, Miguel Ángel, Vivencias, emocionesy perfiles femeninos. Judeoconversas e Inquisición en Aragón en el siglo XV (ANA ECHEVARría ARsuaga)

1007 Solórzano Telechea, Jesús Ángel y Martín PÉrez, Fernando (coords.), Rutas de comunicación marítima y terrestre en los reinos hispánicos durante la Baja Edad Media. Movilidad, conectividad y gobernanza (ENRIQUE JOSÉ RUIZ PILARES)

1013 TORRE, Sandra de la - ETXEBERRIA, Ekaitz - DíAz DE DURANA, José Ramón (coords.), Valer más en la tierra. Poder, violencia y linaje en el País Vasco bajomedieval (ENRIQUE CANTERA MONTENEGRO)

1015 TRILlo SAN José, Carmen, La Vega de Granada a partir de documentación árabe romanceada inédita (1457-1494). Estudio, edición e índices (INMACULADA GONZÁLEZ SOPEÑA)

1019 Val Valdivieso, M. ${ }^{a}$ Isabel - VillanueVa ZubizarReta, Olatz (Coords.), Pero Ansúrez. El conde, su época y su memoria (ENRIQUe CANTERA MONTENEGRO)

1021 Villanueva Morte, Concepción y Fernández de Córdova Miralles, Álvaro, El embajador Claver. Diplomacia y conflicto en las «Guerras de Italia» (1495-1504) (ENRIQUE Cantera Montenegro) 